\title{
Luminescent Iridium Complexes Used in Light- Emitting Electrochemical Cells (LEECs)
}

\author{
Adam F. Henwood ${ }^{1}$ Eli Zysman-Colman'
}

Received: 26 March 2016/Accepted: 9 May 2016

(c) The Author(s) 2016. This article is published with open access at Springerlink.com

\begin{abstract}
Cationic iridium(III) complexes represent the single largest class of emitters used in light emitting electrochemical cells (LEECs). In this chapter, we highlight the state-of-the-art emitters in terms of efficiency and stability in LEEC devices, highlighting blue, green, yellow/orange, red and white devices, and provide an outlook to the future of LEECs.
\end{abstract}

Keywords Light-emitting electrochemical cells · Phosphorescence · Iridium · Electroluminescence

\section{Introduction}

Luminescent materials based on iridium(III) complexes have become the "go to" material when designing emitters for solid-state lighting (SSL) applications. Since the first report of a phosphorescent emitter in an organic light-emitting diode (OLED) [1], iridium complexes have come to be the most widely used class of emitters employed for this purpose by virtue of their efficient spin-orbit coupling (SOC) processes that relax the spin selection rule that otherwise forbids $T_{1}$ to $S_{0}$ transitions [2-4]. In an electroluminescent device, spin statistics necessitates that $75 \%$ of excitons generated in the device are in the triplet state, while the remainder

This article is part of the Topical Collection "Photoluminescent Materials and Electroluminescent Devices"; edited by Nicola Armaroli, Henk Bolink.

Eli Zysman-Colman

eli.zysman-colman@st-andrews.ac.uk;

http://www.zysman-colman.com

1 Organic Semiconductor Centre, EaStCHEM School of Chemistry, University of St Andrews, St Andrews, Fife KY16 9ST, UK 
are in the singlet state. Therefore, iridium complexes are able to harvest $100 \%$ of the excitons.

Aside from OLEDs, an alternative class of organic lighting device that is gaining attention is the light-emitting electrochemical cell (LEEC) [5-8]. In contrast to OLEDs, where the emitter is typically a charge-neutral chromophore, LEECs based on phosphorescent emitters utilize intrinsically charged ionic transition metal complexes (iTMCs) as the emitters in the device. The charged nature of the emitters confers a unique operating mechanism to the LEEC, whereby application of a bias leads to a slow migration of the ions in the device to the relevant electrodes. As this migration occurs, the barrier to charge injection drops significantly, meaning that only low work-function electrodes such as $\mathrm{Au}, \mathrm{Ag}$, or $\mathrm{Al}$ are required to operate these devices. Using air-stable electrodes thereby enables these devices to be solution processed and thus make them potential candidates for industrial scale processing. However, despite the promise of solution processing, to date the performance metrics of LEECs (device efficiency, stability) have remained some way short of their OLED counterparts, and significant improvements are needed if these devices are to become widely adopted in the future.

In this chapter, we will first outline the use of the most frequently employed iridium complex in LEECs, $\left[\operatorname{Ir}(\mathrm{ppy})_{2}(\mathrm{bpy})\right]\left(\mathrm{PF}_{6}\right), \mathbf{1}$, (where ppyH is 2-phenylpyridine and bpy is 2,2'-bipyridine) and demonstrate why its photophysical properties make it an attractive candidate for LEEC applications. We will next detail all the examples where this emitter has been reported in a device and how the performance of different devices changes as a function of study design and device architecture. We will then use the well-understood properties of this complex as a reference to contrast the performance of LEECs employing new emitters that differ from 1 through modulation of the substituents on the ligand scaffolds. In doing so, we will identify champion devices, in terms of efficiency and stability, categorized according to the emission color of the device, covering: blue, green, yellow/orange, red and white devices. We will provide insight into how the physical and chemical properties of the emitters employed in these devices confer such good performances, with a view to informing future molecular design of emitters for LEECs. Finally, we will conclude by offering a perspective on LEECs for the future.

Fig. 1 Structures of $\left[\operatorname{Ir}(\mathrm{ppy})_{2}(\mathrm{bpy})\right]\left(\mathrm{PF}_{6}\right), \mathbf{1}$, and its tert-butyl analogue, [Ir(ppy) $)_{2}$ (dtbubpy)] $\left(\mathrm{PF}_{6}\right), \mathbf{2}$, which are widely studied iridium complexes employed in LEEC devices

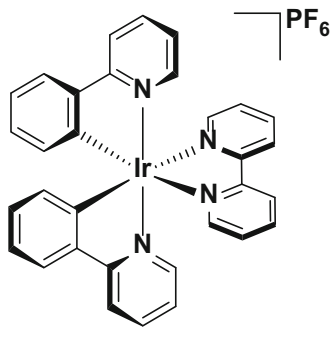

1

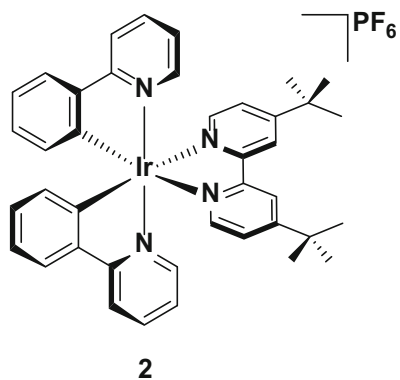




\section{$2\left[\operatorname{Ir}(\text { ppy })_{2}(\right.$ bpy $\left.)\right]\left(\mathrm{PF}_{6}\right)$}

\subsection{Syntheses}

One of the most extensively explored emitters for LEECs is the archetypal cationic iridium complex 1. Although not the first example of an iridium complex tested in a LEEC, (this distinction goes to its cousin, $\left[\operatorname{Ir}(\mathrm{ppy})_{2}(\mathrm{dtbubpy})\right]\left(\mathrm{PF}_{6}\right), 2$, where dtbubpy is $4,4^{\prime}$-di-tert-butyl-2,2'-bipyridine) [9], the simple structure within this large family of cationic complexes makes it a useful reference to compare the performance of LEECs (Fig. 1).

By far the most popular protocol for synthesizing this and related complexes is by the route shown in Scheme 1. The synthesis proceeds first by isolation of the $\mu$ dichloro-bridged cyclometalated iridium dimer intermediate, following refluxing an iridium(III) salt in high boiling alcoholic solvents such as 2-ethoxyethanol, as first demonstrated by Nonoyama in 1974 [10]. Although Nonoyama demonstrated this synthesis using $\mathrm{Na}_{3}\left[\mathrm{IrCl}_{6}\right]$ as the iridium source, $\mathrm{IrCl}_{3} . n \mathrm{H}_{2} \mathrm{O}$ is now by far the most popular source of iridium used for synthesizing these complexes. The dimer can then be easily cleaved in the presence of a neutral $\mathrm{N}^{\wedge} \mathrm{N}$ ligand under mild conditions (such as refluxing DCM/methanol) [11], with the complex isolated as its chloride salt. While the chloride salts of these complexes do function LEECs, chloride anions have been implicated to negatively impact device stability (vide infra) [12] and thus typically the chloride anion is exchanged through a metathesis reaction for a tetrafluoroborate $\left(\mathrm{BF}_{4}{ }^{-}\right)$or most commonly a hexafluorophosphate $\left(\mathrm{PF}_{6}{ }^{-}\right)$anion instead.

The performance of the LEEC can be severely impaired by the presence of trace impurities, such as chloride [12] or water [13]. Therefore, several groups have explored alternative synthetic protocols in order to minimize their presence. For example, the Housecroft group initially demonstrated that chloride-free $\left[\operatorname{Ir}(\mathrm{ppy})_{2}(-\right.$ bpy)] $\left(\mathrm{PF}_{6}\right)$ could be isolated by performing the anion metathesis reaction with a mixture of $\mathrm{NH}_{4} \mathrm{PF}_{6}$ and $\mathrm{AgPF}_{6}$ [12]. Removal of $\mathrm{AgCl}$ by filtration over Celite is facile, leaving the $\mathrm{PF}_{6}{ }^{-}$anion as the only counterion in the sample as confirmed by elemental analysis. Device studies verified the merits of this synthetic route, with the chloride-free samples showing luminance levels roughly double that of samples containing just $1 \%$ chloride. The group's synthetic methodology has evolved since this initial report, with recent efforts demonstrating that cleaving the $\mu$-dichloro-

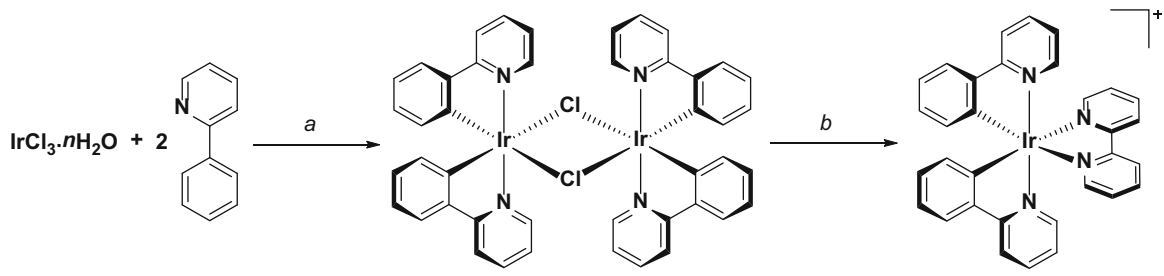

Scheme 1 General protocol for the synthesis of $\left[\operatorname{Ir}(\mathrm{ppy})_{2}(\mathrm{bpy})\right]^{+}$. ${ }^{\mathrm{a}} 2-\mathrm{EtO}-\mathrm{C}_{2} \mathrm{H}_{4} \mathrm{OH} / \mathrm{H}_{2} \mathrm{O}(4: 1 \mathrm{v} / \mathrm{v})$, $110{ }^{\circ} \mathrm{C}, \mathrm{N}_{2}, 19$ h. ${ }^{\mathrm{b}} 2,2^{\prime}$-bipyridyine (2.1 equiv.), $\mathrm{CH}_{2} \mathrm{Cl}_{2} / \mathrm{MeOH}(1: 1 \mathrm{v} / \mathrm{v}), 40{ }^{\circ} \mathrm{C}, \mathrm{N}_{2}, 19 \mathrm{~h}$ 
bridged dimer with a silver salt in the presence of a weakly coordinating solvent allows for isolation of chloride-free solvento-complex intermediates, which can be further reacted with the ancillary ligand to afford the final complexes in excellent purity (and crucially, free of chloride counterions). Devices fabricated from complexes synthesized using this methodology showed exceptionally long-lived stability, with reported $t_{1 / 2}$ values (time taken for the luminance to drop to half its maximum) in excess of $2800 \mathrm{~h}$, even when operated at a notably high pulsed current density of $300 \mathrm{~A} \mathrm{~m}^{-2}$ [14]. These devices will be discussed in more detail in Sect. 5 (Scheme 2).

Alternatively, the Baranoff group has explored using iridium(I) precursor materials in lieu of the more conventional iridium(III) chloride salts. Often, iridium dimers isolated from the $\mathrm{IrCl}_{3} \cdot n \mathrm{H}_{2} \mathrm{O}$ reaction are not pure, but are nevertheless used without purification in the subsequent cleavage step. Purification of the final complex usually involves chromatography and/or recrystallization. However, purifying in this manner can be arduous or sometimes not possible at all. The Baranoff group has shown that the dimer $[\operatorname{Ir}(\mathrm{COD})(\mu-\mathrm{Cl})]_{2}$, bearing labile 1,4cyclooctadiene (COD) ligands, is more amenable to cyclometalation, with reactions proceeding in shorter times (usually $3 \mathrm{~h}$ ) and affording much cleaner isolated dimers that facilitate the final purification process $[15,16]$. They have also reported improved device performance based on materials synthesized in this manner [17] (Scheme 3).

\subsection{Photophysics}

The relevant photophysical and electrochemical data for $\mathbf{1}$ is summarized in Table 1. In acetonitrile solution at room temperature $\mathbf{1}$ is an orange-yellow emitter

(a)

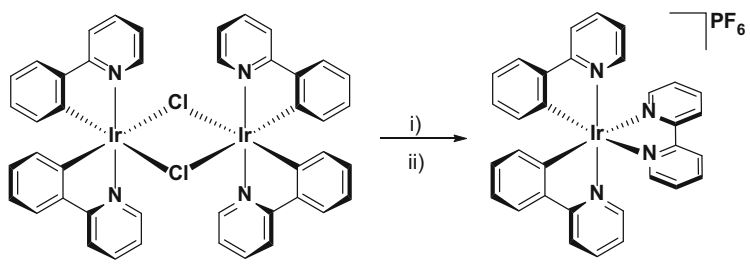

(b)
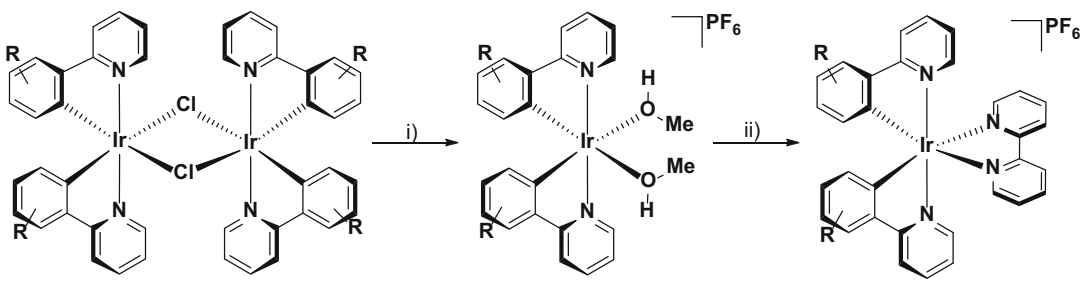

Scheme 2 Two different protocols for isolating chloride-free [ $\left.\operatorname{Ir}(\mathrm{ppy})_{2}(\mathrm{bpy})\right]\left(\mathrm{PF}_{6}\right)$-type complexes reported by Housecroft et al. [14]. a (i) 2,2'-bipyridine (2.0 equiv.), $\mathrm{MeOH}, \mathrm{MW} 120{ }^{\circ} \mathrm{C}, 14$ bar, $2 \mathrm{~h}$; (ii) excess $\mathrm{NH}_{4} \mathrm{PF}_{6}$ and $\mathrm{AgPF}_{6}$, r.t., 1 h. b R is a 4-phenyl substituent or 4,6-diphenyl substituent (i) $\mathrm{MeOH}$, $\mathrm{AgPF}_{6}$, r.t., 2 h; (ii) 2,2'-bipyridine (1.0 equiv.) $\mathrm{MeOH}, \mathrm{NH}_{4} \mathrm{PF}_{6}$, r.t., $1 \mathrm{~h}$ 


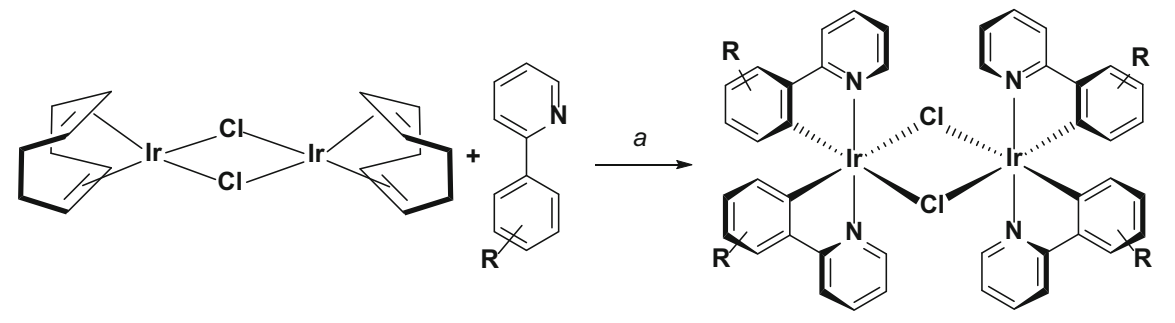

Scheme 3 Protocol for synthesizing $\left[\operatorname{Ir}(\mathrm{ppy})_{2}(\mu-\mathrm{Cl})\right]_{2}$-type dimer complexes from $[\operatorname{Ir}(\mathrm{COD})(\mu-\mathrm{Cl})]$. $\mathrm{R}$ is either an unsubstituted ring or a 2,4-difluorophenyl substituted ring. ${ }^{2}$ - $-\mathrm{EtO}-\mathrm{C}_{2} \mathrm{H}_{4} \mathrm{OH}, 110{ }^{\circ} \mathrm{C}, \mathrm{N}_{2}, 3 \mathrm{~h}$

Table 1 Relevant photophysical parameters for $\left[\operatorname{Ir}(\mathrm{ppy})_{2}(\mathrm{bpy})\right]\left(\mathrm{PF}_{6}\right), \mathbf{1}$

\begin{tabular}{lll}
\hline & $\mathbf{1}$ & References \\
\hline$\lambda_{\mathrm{abs}} / \mathrm{nm}\left[\varepsilon\left(\times 10^{4} / \mathrm{M}^{-1} \mathrm{~cm}^{-1}\right)\right]^{\mathrm{a}}$ & $265[4.17], 310[1.29], 375[0.60], 420[0.26]$ & {$[27]$} \\
$\lambda_{\mathrm{em}(\mathrm{sol})} / \mathrm{nm}^{\mathrm{a}, \mathrm{b}}$ & 605 & {$[22]$} \\
$\lambda_{\mathrm{em}(\mathrm{film})} / \mathrm{nm}^{\mathrm{c}}$ & 587 & {$[21]$} \\
$\Phi_{\mathrm{PL}(\mathrm{sol})} / \%^{\mathrm{b}, \mathrm{d}}$ & 9 & {$[22]$} \\
$\Phi_{\mathrm{PL}(\mathrm{film})} / \%^{\mathrm{c}, \mathrm{e}}$ & 34 & {$[21]$} \\
$\Phi_{\mathrm{PL}(\mathrm{film})} / \%^{\mathrm{e}}$ & 66 & {$[23]$} \\
$\tau_{\mathrm{e}} / \mu \mathrm{s}^{\mathrm{a}, \mathrm{b}}$ & 0.43 & {$[21]$} \\
\hline
\end{tabular}

\footnotetext{
a Measured in $\mathrm{MeCN}$ at $298 \mathrm{~K}$

b Measured under deaerated conditions

c Film composition: 1:1 iridium complex to ionic liquid

${ }^{\mathrm{d}}$ Using $\mathrm{Ru}(\mathrm{bpy})_{3}\left(\mathrm{PF}_{6}\right)_{2}$ as the standard $\left(\Phi_{\mathrm{PL}}=9.5 \%\right.$ in $\left.\mathrm{MeCN}\right)$, and scaled according to this value

e Measured using an integrating sphere
}

with a broad, unstructured emission centered at $585 \mathrm{~nm}$, with a triplet lifetime of $0.43 \mu$ s. This emission profile is characteristic of many $\left[\operatorname{Ir}\left(\mathrm{C}^{\wedge} \mathrm{N}\right)_{2}\left(\mathrm{~N}^{\wedge} \mathrm{N}\right)\right]^{+}$ complexes, identified by Güdel as comprising a mixed charge transfer (CT, Fig. 2) triplet excited state consisting of CT transitions between the metal and the $\mathrm{N}^{\wedge} \mathrm{N}$ ancillary ligand (metal-to-ligand charge transfer, ${ }^{3} \mathrm{MLCT}$ ) and between the phenyl groups of the $\mathrm{C}^{\wedge} \mathrm{N}$ ligands and the $\mathrm{N}^{\wedge} \mathrm{N}$ ancillary ligand (ligand-to-ligand charge transfer, ${ }^{3}$ LLCT) [18-20]. The spin density of the triplet state is thus delocalized over the entire complex (Fig. 3). Upon cooling to $77 \mathrm{~K}$, the emission is hypsochromically shifted but remains unstructured. This rigidochromic blueshifting of the emission upon cooling is a further hallmark of the mixed CT nature of the emission, which is stabilized at ambient temperature by polar aprotic solvents such as MeCN. Aside from ${ }^{3} \mathrm{MLCT} /{ }^{3} \mathrm{LLCT}$ excited states, $\left[\operatorname{Ir}\left(\mathrm{C}^{\wedge} \mathrm{N}\right)_{2}\left(\mathrm{~N}^{\wedge} \mathrm{N}\right)\right]^{+}$ complexes can also demonstrate structured emission profiles that are attributed to centered radiative decay $\left({ }^{3} \mathrm{LC}\right)$. It is not uncommon for cationic iridium complexes to exhibit emission from a mixture of ${ }^{3} \mathrm{LC}$ and ${ }^{3} \mathrm{MLCT} /{ }^{3} \mathrm{LLCT}$ states [3].

The photophysical properties of many iridium complexes in the solid state are very different to the solution state. In the case of $\mathbf{1}$, the emission energy in thin films 


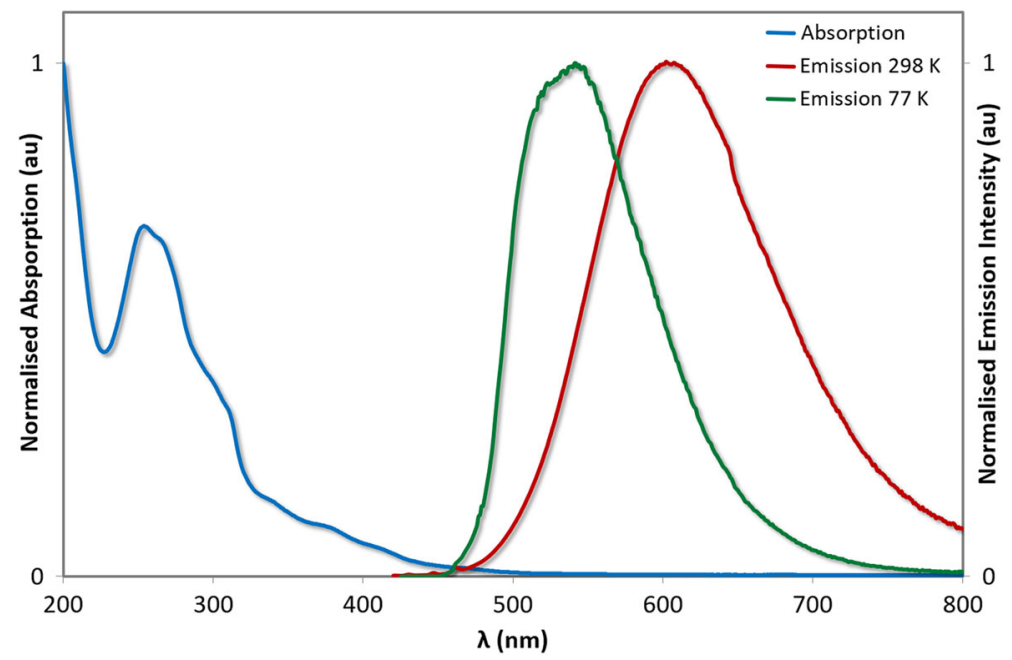

Fig. 2 UV-Vis absorption spectra and emission spectra of $\mathbf{1}$ in MeCN. $77 \mathrm{~K}$ emission spectrum of 1 in 2-MeTHF
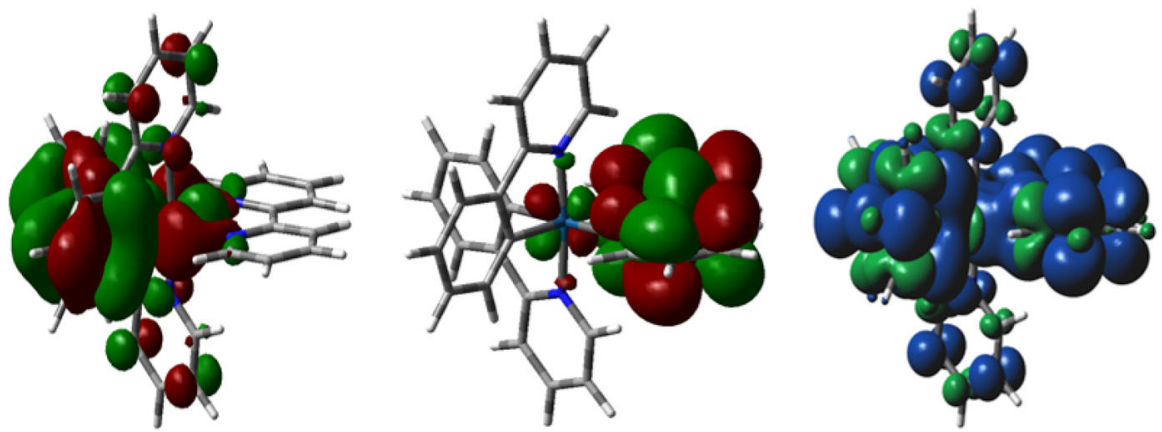

Fig. 3 DFT computed Kohn-Sham orbitals for the HOMO (left) and LUMO (middle) of 1. Spin density of the $T_{1}$ state of $\mathbf{1}$ (right)

compared to $\mathrm{MeCN}$ solution is virtually unchanged (a somewhat rare phenomenon), but the $\Phi_{\mathrm{PL}}$ values differ dramatically. Reports of the $\Phi_{\mathrm{PL}}$ of 1 in MeCN have been somewhat variable ranging from 6 to $14 \%$ [21, 22], but ultimately are rather low, while in the 'LEEC' film (containing the complex and an ionic liquid, IL, additive in a 1:1 molar ratio) or in a doped film (5 wt $\%$ in PMMA) the $\Phi_{\mathrm{PL}}$ values are substantially higher (34\% [21] and $66 \%$ [23], respectively). The increased brightness in the solid state is plausibly attributed to rigidification of the local environment that inhibits molecular motions that otherwise non-radiatively deactivate the excited state. Although clearly a desirable feature, such effects are difficult to predict, with this rigidification phenomenon often in competition with self-quenching processes that lower the $\Phi_{\mathrm{PL}}$. Self-quenching is particularly 


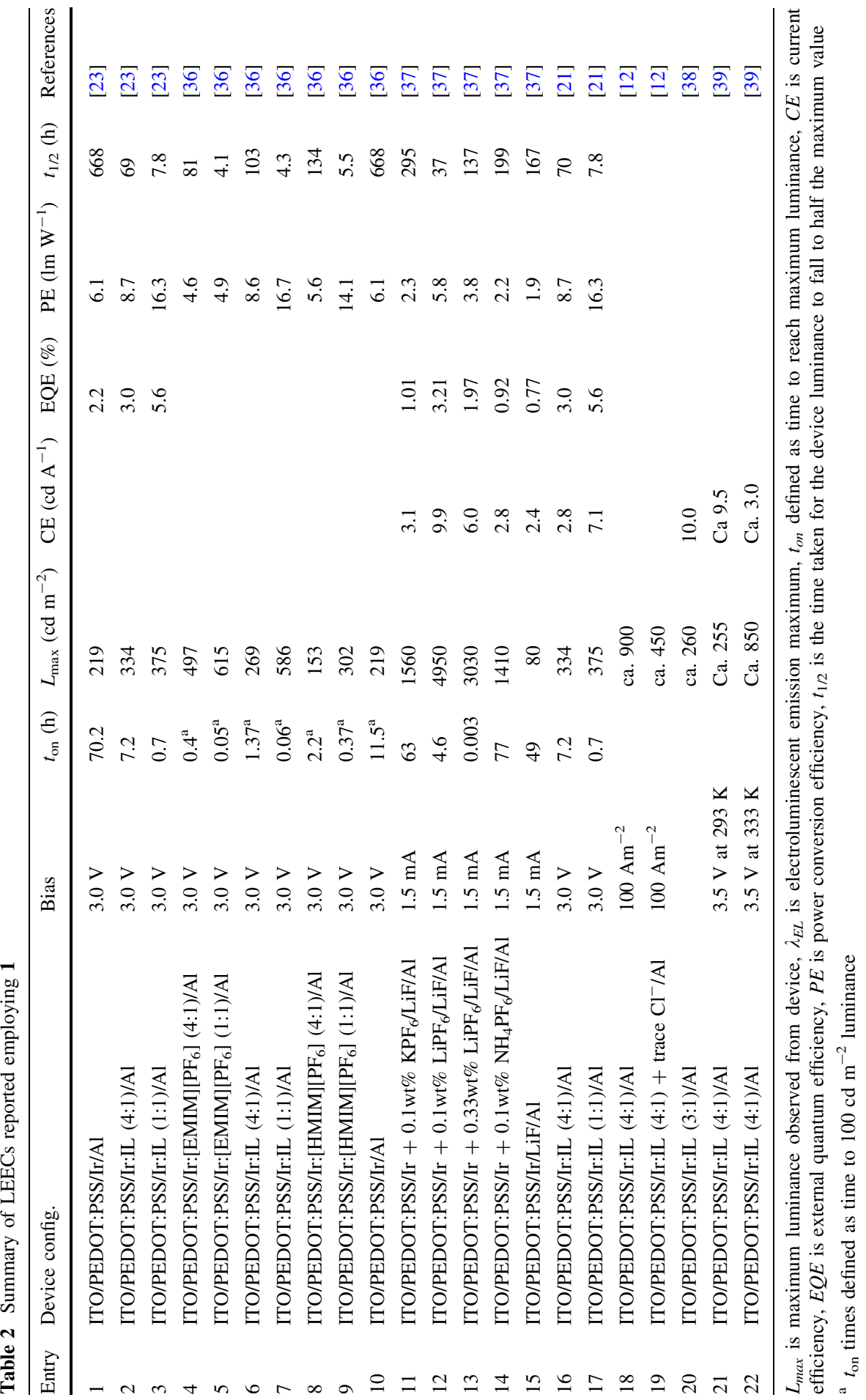


problematic for LEECs since, unlike OLEDs, the emitters are not normally doped into host matrices; typically, the emissive layers are neat films or contain small amounts of IL doped into the host emitter (4:1 and 1:1 weight by weight ratios are the most common configurations), leading to films that show lower $\Phi_{\mathrm{PL}}$ compared to solution and thus lower device efficiencies as well. Furthermore, the emission energies of these complexes can change substantially in the solid state. Small red shifts frequently occur due to effects such as aggregate formation but on occasion substantial red-shifting (as high as $71 \mathrm{~nm}$, or $2037 \mathrm{~cm}^{-1}$ ) [24] or even blue-shifting have been reported [25, 26]. The example given here for $\mathbf{1}$ demonstrates some of these effects, but they will be revisited in multiple instances throughout this chapter.

Aside from characterizing its photophysical parameters, it is important to determine the electrochemical properties of these complexes as well. Normally, this is done in order to estimate the energies of the HOMO and LUMO levels [28, 29]. These values are particularly important in the context of OLEDs so that the energy levels of the emissive material can properly align with those of the host materials and charge transport layers. For LEECs, this consideration is only important when aligning the energy levels of host-guest systems [30-32], but not for more traditional 'single emitter' devices since the emitters here also carry out the role of charge transport. The dual charge transport/light-emitting role of the iTMCs in the device is the most important contributing factor for explaining why LEECs are invariably less stable than their OLED counterparts. Thus, an important feature to look for when characterizing the electrochemical properties of the emitter is for reversible oxidation and reduction waves since good reversibility suggests that the emitter might be more resilient to electrochemical degradation when operating in the device.

With the support of DFT calculations (Fig. 3), the nature of the oxidation and reduction of 1 has been assigned. The oxidation is ascribed to the $\mathrm{Ir}^{\mathrm{III} / \mathrm{IV}}$ redox couple combined with contribution from the phenyl rings of the cyclometalating ligands. The degree of reversibility of this redox couple depends on the magnitude of the contribution from the $\mathrm{C}^{\wedge} \mathrm{N}$ ligands; greater contributions results in a greater degree of irreversible electrochemistry. The reduction is assigned to a highly reversible bpy ${ }^{0 / 1-}$ redox couple, which is believed to be an important factor in giving devices based on 1 impressive stability metrics $\left(t_{1 / 2}=668 \mathrm{~h}\right.$, vide infra) [23].

\subsection{Devices}

To the best of our knowledge, 1 represents the most investigated iTMC emitter in an LEEC. The performances of all of the devices using $\mathbf{1}$ have been summarized in Table 2. The device architectures are somewhat more complex than the simplest reported LEECs, which themselves are single layer devices comprised of a neat film of emissive iTMCs sandwiched between a transparent conducting anode, usually indium tin oxide (ITO), and an air-stable cathode such as gold, silver, or aluminium. The ability to use air-stable, high-work-function electrodes is an advantageous characteristic of LEECs compared to OLEDs. 
Upon application of an external bias to the LEEC, there is a large initial barrier to charge injection. As migration of the ions in the emissive layers progresses, an electric double layer forms and the barrier to injection drops significantly until eventually charge injection at very low driving voltages (typically ca. $3 \mathrm{~V}$ ) becomes facile. A charge-hopping mechanism ensues akin to that found in an OLED and emission is realized upon radiative decay of the formed exciton.

Although these single-layer devices readily generate light, various groups have shown in the last decade that small modifications to the device architecture can yield vastly improved LEEC performance. Figure 4 depicts these modifications in what can now be considered the most popular device architecture for LEECs, bearing two crucial features that differentiate it from the early reports. As mentioned, LEECs do not require charge-injecting layers to function, but nevertheless the ITO anode is invariably coated with PEDOT:PSS (an electrically conducting mixture of poly(3,4ethylenedioxythiophene) and poly(styrenesulfonate)) since it facilitates the formation of uniform iTMC thin films on the ITO substrate and it improves hole injection. Devices fabricated in the absence of PEDOT:PSS are prone to forming crystallinelike domains within the film, which can have deleterious effects on the device performance and batch-to-batch reproducibility [33-35].

These two-layer devices nevertheless can give good performance, provided that the optoelectronic properties of the iTMC are also favorable. Entry 1 effectively demonstrates this principle with the device based on $\mathbf{1}$ exhibiting a remarkably long lifetime of $668 \mathrm{~h}$. The authors attribute this stability to the relatively large calculated ${ }^{3} \mathrm{MC}-\mathrm{T}_{1}$ energy gap for 1 [23]. Theory and experimental observations have implicated ${ }^{3} \mathrm{MC}$ states in an elongation of the $\mathrm{N}_{\text {pyridyl }} \mathrm{Ir}$ bond of the $\mathrm{C}^{\wedge} \mathrm{N}$ ligands of $\left[\operatorname{Ir}\left(\mathrm{C}^{\wedge} \mathrm{N}\right)_{2}\left(\mathrm{~N}^{\wedge} \mathrm{N}\right)\right]^{+}$complexes, which accounts for the efficient nonradiative quenching resulting from these states [40]. In addition, work on ruthenium(II) complexes has suggested that this bond lengthening/breaking process within the ${ }^{3} \mathrm{MC}$ state introduces a free coordination site that allows small molecules such as water to coordinate to the metal, quenching the emission and leading to degradation products within the device [13, 41]. Thus, devices employing complexes with a small ${ }^{3} \mathrm{MC}-\mathrm{T}_{1}$ energy gap tend to not be stable unlike the case with 1 where the device stability is enhanced. In addition, the reversible electrochemistry in $\mathbf{1}$ results in its capacity to act as an effective charge transport material and thereby resist electrochemical degradation processes that also impact device lifetimes.

Aside from the addition of PEDOT:PSS, an IL additive is also normally doped into the emissive layer to enhance charge mobility and to reduce turn-on times $\left(t_{\mathrm{on}}\right.$,

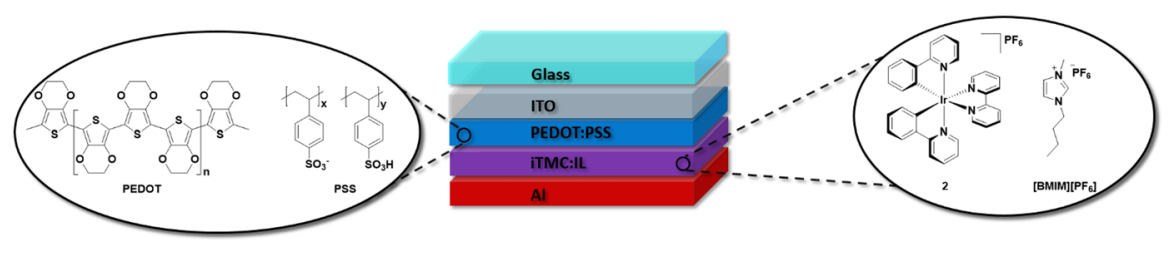

Fig. 4 Typical device architecture of a LEEC employing 1 as the emissive layer 
defined as the time taken to reach maximum luminance under constant bias) [42]. The most common IL used in LEECs is 1-butyl-3-methylimidazolium hexafluorophosphate, $[\mathrm{BMIM}]\left[\mathrm{PF}_{6}\right]$. Entries 1-3, Table 2, demonstrate the remarkable differences in LEEC performance produced by just varying the ratio of $\mathbf{1}$ and $[\mathrm{BMIM}]\left[\mathrm{PF}_{6}\right]$ in an otherwise identical device configuration [23]. In the absence of $\mathrm{IL}$, an extremely long $t_{\mathrm{on}}$ of more than $70 \mathrm{~h}$ is observed. This is attributed to low ionic mobility of the $\mathrm{PF}_{6}{ }^{-}$anions, possibly due to the formation of microcrystalline domains in the film. Addition of IL circumvents this problem, improving ionic conductivity and thus charge transport in the device in addition to disrupting any possible crystallite formation. Entries 2 and 3, Table 2, show the performances of two devices with different weight ratios of iTMC to IL (4:1 and 1:1, respectively). Both devices show improved $t_{\text {on }}$ times $(7.2$ and $0.7 \mathrm{~h}$, respectively) as well as improved EQEs (3.0 and $5.6 \%$, respectively); where EQE is the external quantum efficiency, defined as the ratio of electrons injected into the device to photons outcoupled from the device. However, the addition of IL comes at the considerable cost of device stability as measured by its lifetime, $t_{1 / 2}\left(t_{1 / 2}\right.$, defined as the time taken for the device to reach half of its maximum luminance). In the absence of IL, this device lasts for up to $668 \mathrm{~h}$, but lifetimes are dramatically reduced for the devices constituting iTMC:IL ratios of 4:1 (69 h) and 1:1 (7.8 h). This further reduction of device stability with increasing amounts of IL is representative of the behavior in LEECs, regardless of iTMC emitter, and illustrates the trade-off between $t_{1 / 2}$ and $t_{\mathrm{on}}$ that has been a significant challenge to overcome. The compromise between attaining good device performance (EQEs, $t_{\mathrm{on}}$ ) and reasonable device lifetimes has meant the most popular iTMC:IL ratio employed has been 4:1 weight by weight.

Significant efforts have been expended to overcome this compromise in device performance. The most successful strategy is based on application of a pulsed current driving method in place of the more established constant voltage method and will be discussed multiple times in the following sections of this chapter. The majority of the remaining entries in Table 2 illustrate other approaches researchers have taken to tackle this issue, which will be discussed here.

Entries 4-10 summarize a study undertaken by Bolink et al. [36] to elucidate how using different ILs impact $t_{\mathrm{on}}$. It should be noted that in this study they define $t_{\mathrm{on}}$ as the time taken for the LEEC to reach $100 \mathrm{~cd} \mathrm{~m}^{-2}$, as opposed to maximum luminance in the device. The study uses ILs comprised of imidazolium cations of differing $N$-alkyl chain length: 1-ethyl-, 1-butyl- and 1-hexyl-3-methylimidazolium, each as their hexafluorophosphate salts. They demonstrated that the ethyl analogue, which is the most conducting IL, demonstrated the fastest $t_{\text {on }}$ times $(0.4 \mathrm{~h}$ for $4: 1$ iTMC:IL ratio). Although the $t_{1 / 2}$ value was lowest for this IL, it was reasoned that the higher luminance values observed for this device were the major contributing factor for this shortened $t_{1 / 2}$ and that actually the overall device stability had not been significantly impacted even when compared with the control device bearing no IL. Nevertheless, despite this study, $[\mathrm{BMIM}]\left[\mathrm{PF}_{6}\right]$ is still the most popular choice of ionic liquid.

In a similar guise, entries 11-15 and Table 2, summarize the recent contribution by Slinker et al. [37] where they explored the effect on the response time of doping 
in inorganic salt additives. They reasoned that the large size of the iTMC cations renders the complexes to be essentially stationary in the device, meaning that upon initial application of a bias, the cation density at the cathode is initially much lower than the anion concentration at the anode, leading to an imbalance of charge injection into the device. However, by doping in small amounts of alkali metal cation hexafluorophosphate salts, they demonstrated that indeed fast $t_{\mathrm{on}}$ times under constant current conditions can be achieved, with the $\mathrm{LiPF}_{6}$ additive showing the best performance due to the small size of the $\mathrm{Li}^{+}$cation. Crucially, this also led to more balanced charge injection that ultimately improved not just response times, but also luminance values and EQEs.

Aside from functioning as a useful standard for exploring new device physics, 1 also serves as a helpful reference compound for chemists to compare the performance of devices operating with new emitters. However, as alluded to above, reproducibility across devices can be a challenge. Entries 1 and 10, 2 and 16, and 3 and 17 reproduce each other well. However, comparison of entries 2 and 3 with the corresponding devices in entries 6 and 7 demonstrates considerable variation in device performance. The device in entry 6 in particular shows significant differences in the luminance $\left(269 \mathrm{~cd} \mathrm{~m}^{-2}\right)$ and $t_{1 / 2}(103 \mathrm{~h})$ values compared with its counterpart LEEC in entry $2\left(334 \mathrm{~cd} \mathrm{~m}^{-2}\right.$ and $\left.69 \mathrm{~h}\right)$. Housecroft and co-workers have recently addressed this issue, demonstrating that the poor batch-to-batch reproducibility of these devices was attributable at least in part to trace $\mathrm{Cl}^{-}$in the sample [12]. As outlined above, using silver salt-assisted syntheses they were able to isolate 1 with improved purity, leading to devices with superior luminance levels (ca. $900 \mathrm{~cd} \mathrm{~m}^{-2}$, entry 18) compared with those containing trace chloride impurities (ca $450 \mathrm{~cd} \mathrm{~m}^{-2}$, entry 19). High-purity samples are crucial for achieving good device performance, and indeed aside from the presence of $\mathrm{Cl}^{-}$, trace water has also been implicated in impacting device performances of ruthenium-based LEECs [13].

Entries 20-22 are beyond the scope of this discussion, with the relevant references discussing the device physics surrounding the peculiar operational mechanism of LEECs. They are included for the reader's reference to illustrate additional examples reported where $\mathbf{1}$ has been the constituent emitter in the LEEC $[38,39]$.

\section{Blue}

To date, attaining simultaneously efficient, stable, and deep-blue-emitting LEECs remains the most pressing issue for LEEC development. The challenge of obtaining high-performance blue-emitting devices is well-known for both organic and inorganic light-emitting devices, and while it has largely been addressed in the former case, this topic is still the source of very active research for OLEDs. For example, a recent report detailed the performance of a new champion blue OLED, which showed simultaneously deep-blue emission and high device efficiency $(\mathrm{EQE}=10.1 \%)$ [43]. However, this efficiency value still falls well below the efficiencies reported for red or green (EQE 30\%), or even sky-blue OLEDs $(\mathrm{EQE}>20 \%)$ [4]. 


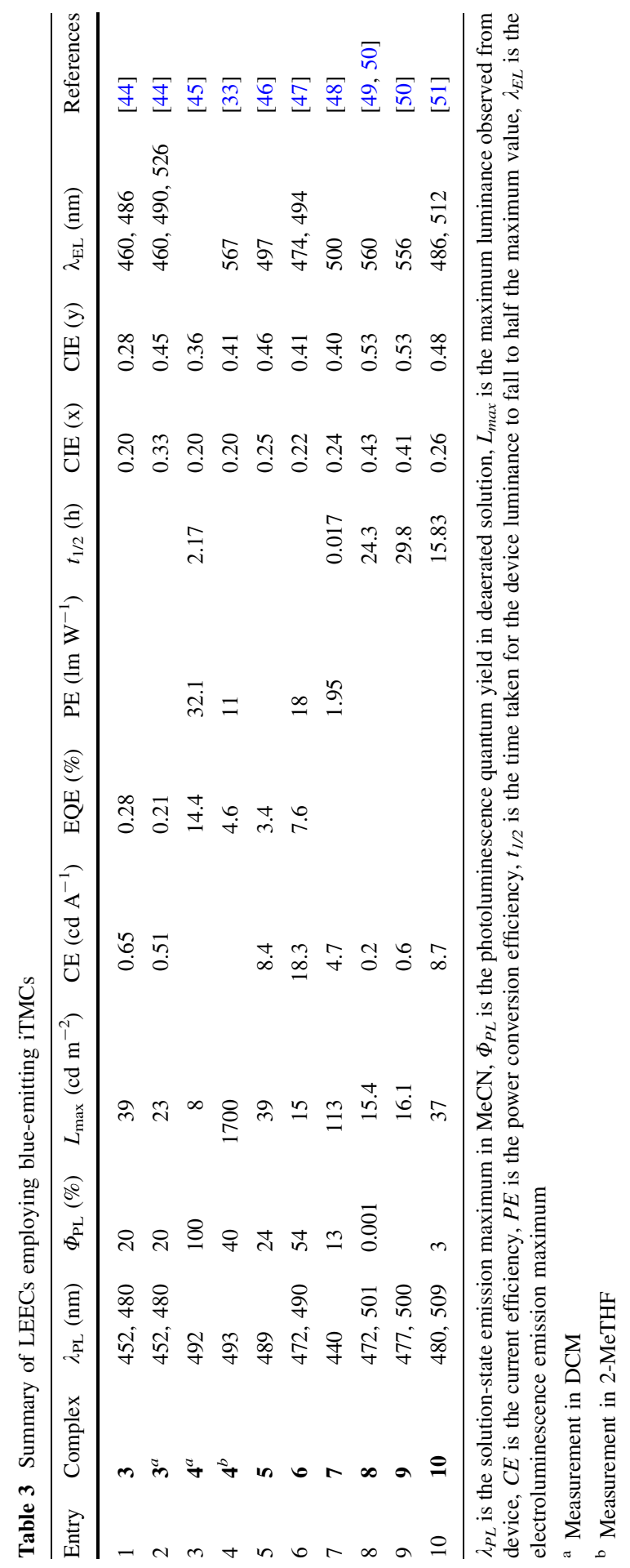


In the case of LEECs, the situation is more dire. To date, no LEEC has even been reported emitting blue light close to the 'ideal deep blue' CIE coordinate (CIE: 0.15, 0.06 , as defined by the European Broadcast Union, EBU), let alone with good efficiency. Furthermore, the stability of these sky-blue LEECs is demonstrably inferior than their OLED counterparts; device lifetimes are often in the tens of hours at best, compared with thousands of hours reported for yellow or orange LEECs. Given that blue is a necessity in attaining white light from a typical RGB color combination, overcoming this issue is of pressing concern. A summary of the relevant performance metrics of blue LEECs discussed herein is given in Table 3.

\subsection{Efficiency}

The widely accepted paradigm to achieve blue emission requires that the HOMO be stabilized with electron-withdrawing groups located on the phenyl ring of the $\mathrm{C}^{\wedge} \mathrm{N}$ ligands and the LUMO be destabilized with electron-donating groups located on the ancillary $\mathrm{N}^{\wedge} \mathrm{N}$ ligand. The most commonly used electron-withdrawing groups used are fluorine atoms [52] with examples of complexes shown in Fig. 5. Further blueshifting of the emission can be achieved by incorporating electron-rich heterocycles within the ligand frameworks of either the $N^{\wedge} N(3)$ or $C^{\wedge} N(4)$ ligands $[33,44,45]$. This strategy is most effective when this structural modification occurs within the ancillary ligand, as exemplified by the greater blue shift in emission observed for $\mathbf{3}$ $\left(\lambda_{\mathrm{PL}}=451,484 \mathrm{~nm}\right.$ in MeCN) compared to $4\left(\lambda_{\mathrm{PL}}=492 \mathrm{~nm}\right.$ in DCM $)$.

The blue emission in solution observed for $\mathbf{3}$ translates to its performance in the device, with CIE coordinates in the sky blue of (CIE: 0.20, 0.28). Despite being reported in 2008, this LEEC nevertheless remains the bluest reported for any iridium emitter to date. However, the emission observed for this device is still a long way from the ideal 'deep-blue' coordinates required in RGB devices (CIE 0.15, 0.06). Furthermore, this device functions in the absence of ionic liquid, which results in essentially impractical turn on times $\left(t_{\text {on }}=7.1 \mathrm{~h}\right)$. When an ionic liquid dopant is added, the response time shortens dramatically $\left(t_{\mathrm{on}}=1.1 \mathrm{~h}\right)$ but the observed color is also greatly red-shifted (CIE 0.33, 0.45). Aside from the device based on 3 achieving the bluest emission reported to date, the performance of $\mathbf{3}$ in the device is relatively poor, with low efficiencies and brightness levels reported for both the IL

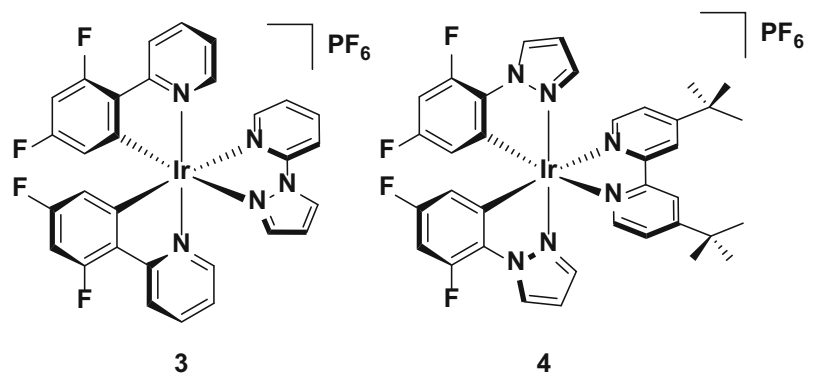

Fig. 5 Blue-emitting iridium complexes bearing pyrazole-type ligands 
free device $\left(\mathrm{EQE}=0.28 \%, \quad L_{\max }=39 \mathrm{~cd} \mathrm{~m}^{-2}\right)$ and IL-doped device $\left(\mathrm{EQE}=0.21 \%, L_{\max }=23 \mathrm{~cd} \mathrm{~m}^{-2}\right)$.

By contrast, although complex 4 displays an emission profile that is strongly redshifted compared to $\mathbf{3}$, it is a much more efficient emitter in the device. Indeed, this high efficiency has made it a favored choice of emitter either for blue-emitting LEECs [30, 33, 53], or as the blue component in white LEECs [45, 54-56]. The performance of this emitter in white LEECs will be revisited in Sect. 7.

As a blue/blue-green emitter, the device reported based on 4 displays extraordinarily high device efficiencies $\left(\mathrm{EQE}=14.4 \%\right.$, P. E. $\left.=32.1 \mathrm{~lm} \mathrm{~W} \mathrm{~m}^{-1}\right)$. These values can vary significantly, depending on the device architecture. For example, the first reported LEEC employing this complex gave a comparably low overall EQE of $4.4 \%$, using a typical device architecture of ITO/PEDOT:PSS/Ir/Al. However, it is worth noting that this device displays very high brightness for a LEEC (entry $4, L_{\max }=1700 \mathrm{~cd} \mathrm{~m}^{-2}$ ) [33]. Since then, Wong in particular has explored different means by which charge injection and transport can be improved using this complex as an emitter. For example, it was shown that by doping small amounts (up to $1.0 \mathrm{wt} \%$ ) of a pure organic NIR emitting laser dye, 3,3'-diethyl2,2'-oxathiacarbocyanine iodide, DOTCI, (Fig. 6) into the emissive layer of complex 4, higher device efficiencies could be obtained (EQE $=12.8 \%$ for 0.01 wt \% DOTCI) than without any dopant $(\mathrm{EQE}=9.06 \%$ for the pristine device DOTCI) [57]. The intrinsic hole transporting properties of $\mathbf{4}$ leads to the formation of the charge recombination zone near the cathode, which facilitates exciton quenching. This charge imbalance can be mitigated by doping in DOTCI. DOTCI has a much higher HOMO than $\mathbf{4}$ and therefore impedes hole transport but has a similar LUMO that thereby keeps electron mobility balanced. Furthermore, the poor spectral overlap between the emission of $\mathbf{4}$ and the absorption of DOTCI results in minimal quenching of the iridium-based emission by energy transfer to the guest, which would otherwise negatively impact the efficiency of the device.

Aside from exploring dopants, Wong has also used $\mathbf{4}$ to study the effects of incorporation of additional layers to the LEEC architecture to further balance charge transport. The archetypal device based on 4 (ITO/PEDOT:PSS/4/Ag) gave reasonably good efficiencies $(\mathrm{EQE}=8.5 \%)$. However, the efficiency of the device could be further improved by incorporating a high work function cathode within the device (ITO/PEDOT:PSS/4/Ca/Ag, $\mathrm{EQE}=9.6 \%$ ) and adding a hole injecting layer as well (ITO/PEDOT:PSS/TPD/4/Ca/Ag, EQE $=10.5 \%)$. It should be noted that the strong hole transporting characteristics of $\mathbf{4}$ meant that addition of only the hole injecting layer actually impeded device efficiencies (ITO/PEDOT:PSS/TPD/4/ $\mathrm{Ag}, \mathrm{EQE}=6.8 \%$ ), providing further evidence of the necessity of balancing charge injection and transport in the device (Fig. 7).

Fig. 6 Organic dopant used by Wong to improve the efficiencies of $\mathbf{4}$

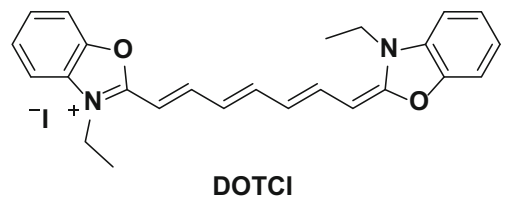




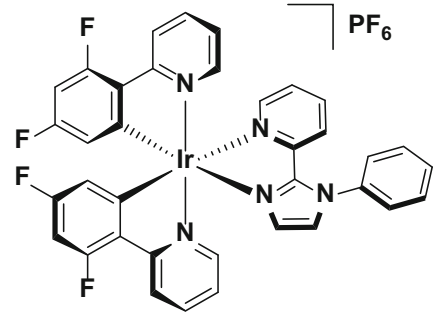

5

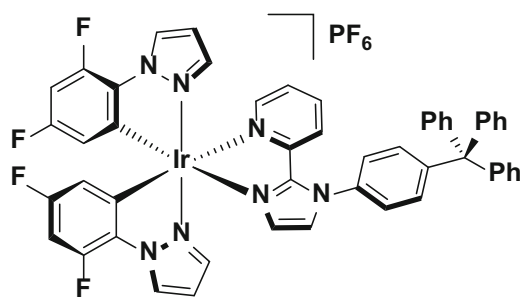

6

Fig. 7 Iridium complexes bearing pyridylimidazole ancillary ligands

A different strategy that has been used to improve device efficiencies is by adding steric bulk to the complex to inhibit intermolecular quenching processes. Complexes 5 and $\mathbf{6}$ demonstrate this strategy. Both complexes are blue-green emitters in acetonitrile solution $\left(\lambda_{\mathrm{PL}}=489 \mathrm{~nm}\right.$ for $\mathbf{5}$ and $472,490 \mathrm{~nm}$ for $\left.\mathbf{6}\right)$, with $\mathbf{6}$ blue-shifted due to the additional pyrazole rings incorporated within the cyclometalating ligands. The most important structural difference between $\mathbf{5}$ and $\mathbf{6}$ is the presence of the trityl group on the ancillary ligand of $\mathbf{6}$. This bulky unit serves to increase the molecular spacing between emissive molecules in the film, which leads to reduced excited-state self-quenching that negatively impacts the device efficiencies. Indeed, despite $\mathbf{6}$ being moderately blue-shifted both in solution and in the device $\left(\lambda_{\mathrm{EL}}=474,494 \mathrm{~nm}\right.$, CIE $\left.0.22,0.41\right)$ compared to $5\left(\lambda_{\mathrm{EL}}=497 \mathrm{~nm}\right.$, CIE $0.25,0.46$ ), the LEEC with $\mathbf{6}$ shows greatly improved efficiencies $\left(\mathrm{CE}=8.4 \mathrm{~cd} \mathrm{~A}^{-1}\right.$ for $\mathbf{5}$ and $18.3 \mathrm{~cd} \mathrm{~A}^{-1}$ for $\mathbf{6}$; $\mathrm{EQE}=3.4 \%$ for $\mathbf{5}$ and $7.6 \%$ for $\mathbf{6})$.

Finally, complex 7 represents the unpredictability in designing new blue emitters for devices. For the ancillary ligand, this complex uses $N$-heterocylic carbenes (NHCs), which are very strongly $\sigma$-donating heterocycles that can strongly destabilize the LUMO, invoking a significant blue shift in the emission. The potency of these heterocycles is well known, with near-UV emission having been reported for iridium complexes containing multiple NHCs within the ligand frameworks

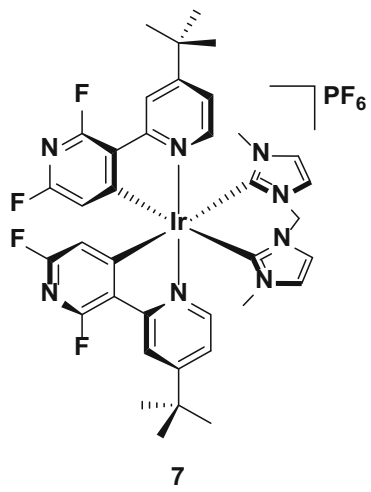

Fig. 8 Blue-emitting iridium complex bearing an NHC ancillary ligand 
$[43,58]$. Furthermore, the cyclometalating ligand incorporates a nitrogen ring into the 5-position of the cyclometalating ring. This nitrogen acts as a strongly $\sigma$ withdrawing unit that serves to stabilize the HOMO in concert with the fluorine rings in the 4,6-positions. Thus, in solution, 7 is the bluest emitter reported to date to have been incorporated into a $\operatorname{LEEC}\left(\lambda_{\mathrm{PL}}=440 \mathrm{~nm}\right)$ - significantly bluer than complexes $\mathbf{3}$ to $\mathbf{6}$. Unfortunately, for all the effort to blue shift the emission of this complex, ultimately the color of the device is red-shifted, even in comparison with the devices discussed above ( $\lambda_{\mathrm{EL}}=500 \mathrm{~nm}$, CIE 0.24, 0.40) (Fig. 8).

\subsection{Stability}

Although the examples above have demonstrated that high efficiencies are possible for sky-blue LEECs, the two most significant issues still to be addressed with these LEECs is their lack of deep-blue color and crucially their poor stability. There are many reasons for the poor stability of these devices, but one factor in particular thought to be contributing to poorer device performance is the presence of $\mathrm{C}_{\text {aryl }}-\mathrm{F}$ bonds on the cyclometalating ligands. It has been posited that the highly electron deficient $\mathrm{C}^{\wedge} \mathrm{N}$ ligands make them susceptible to chemical degradation by nucleophilic aromatic substitution of the fluorine substituent. A study by Bolink and co-workers[16a] on the stability of fluorine-containing green-emitting iridium complexes will be outlined in more detail in Sect. 4, but it is worth noting here that they demonstrated that of the four complexes studied, the complex bearing four fluorine substituents was far less stable than others bearing just two fluorine atoms, providing indirect evidence that indeed (multiply) fluorinated aromatic rings can be implicated in the electrochemical degradation of the emitter in the device. Similar degradation processes are believed to be operative in OLEDs [59, 60], but the harsher environment in the emissive layer of a LEEC means that this effect is more pronounced in this class of electroluminescent device. Thus, there is interest in designing new emitters that emit blue light without the need for fluorine substituents that might negatively impact the stability. In addition, there is interest in adopting hydrophobic substituents within the ligand framework to impede nucleophiles from coordinating to the iridium center and quenching the emission. These two strategies are exemplified by complexes $\mathbf{8}$ and $\mathbf{9}$, with $\mathbf{9}$ in particular representing an all-in-one effort to achieve blue emission without impacting the device stability.

Like 7, complexes 8 and 9 use NHCs within the ancillary ligand to destabilize the LUMO of these complexes. Despite both complexes bearing just ppy as the $\mathrm{C}^{\wedge} \mathrm{N}$ ligands, they are both blue-green emitters in acetonitrile solution ( $\lambda_{\mathrm{PL}}=472$, $501 \mathrm{~nm}$ for 8 and 477, $500 \mathrm{~nm}$ for 9), with emission strongly blue-shifted and more ligand-centered compared to $1\left(\lambda_{\mathrm{PL}}=605 \mathrm{~nm}\right)[49,50]$ thereby demonstrating the feasibility of blue-shifting emission without using fluorine.

Aside from the fluorine-free cyclometalating ligands, 9 also adopts the common intramolecular $\pi$-stacking strategy for improving the stability of the emitter in the device, utilizing a pendent phenyl substituent on the $\mathrm{N}^{\wedge} \mathrm{N}$ ancillary ligand. This ring is predisposed to form an intramolecular $\pi$-stacking interaction with the phenyl ring of one of the $\mathrm{C}^{\wedge} \mathrm{N}$ ligands, enveloping the iridium core in a supramolecularly caged hydrophobic scaffold that shields it from adventitious attack from prospective 
nucleophiles in the device that degrade the emitter [14, 61, 62]. This substitution pattern is more common for six-membered ring systems, such as the ligand 6-phenyl-2,2'-bipyridine (see Sect. 5 for examples), since the intramolecular $\pi$ stacking distance is usually shorter than in the case of five-membered rings such as the imidazolium ring in $\mathbf{9}$, and is thus more effective at shielding the iridium core (Fig. 9).

The results of combining a fluorine-free ligand scaffold with an intramolecular $\pi$ stacking interaction do appear to improve the stability of the emitter. The devices with both $\mathbf{8}$ and $\mathbf{9}$ are much longer lived $\left(t_{1 / 2}=24.3 \mathrm{~h}\right.$ for $\mathbf{8}$ and $29.8 \mathrm{~h}$ for $\left.\mathbf{9}\right)$ than any of the LEECs with other blue/blue-green emitters discussed so far (e.g., $t_{1 / 2}=2.17 \mathrm{~h}$ for 4 ), pointing to some extent to the merits of this strategy. However, it is important to note that the devices based on these materials are also greatly redshifted. While they are blue-green in solution, the devices are essentially yellowgreen $\left(\lambda_{\mathrm{EL}}=560 \mathrm{~nm}\right.$ for 8 and $556 \mathrm{~nm}$ for 9; CIE: $0.43,0.53$ for 8 and $0.41,0.53$ for 9), which is at least partly accountable for the improved device lifetimes. In addition, although there is a slight improvement in the device lifetime of the LEEC with 9 over that with $\mathbf{8}$, this effect is not as pronounced as for some examples that will be discussed below. This is because the intramolecular $\pi$-stacking interaction in this complex is not as strong as it is for others based on 6-membered ring systems.

Finally, the use of complex 10, a structurally related analogue of $\mathbf{9}$, also attempts to combine strategies for improving stability with strategies for achieving blue emission. The ancillary ligand in this instance contains a pyrazole with coordination through the nitrogen. Complex 10, like 9, is fluorine-free and has an intramolecular $\pi$-stacking ring. This complex is red-shifted in MeCN solution compared to 8 or $\mathbf{9}$ $\left(\lambda_{\mathrm{PL}}=480,509 \mathrm{~nm}\right)$ but, surprisingly, is much bluer in the device, essentially retaining its solution-state emission characteristics $\left(\lambda_{\mathrm{EL}}=486,512 \mathrm{~nm}\right.$; CIE: 0.26 , 0.48). The blue-shifted emission appears to impact the stability, however, with a lower device lifetime $\left(t_{1 / 2}=15.83 \mathrm{~h}\right)$ compared to the LEECs with 8 or 9 . The lower device stability for the device with $\mathbf{1 0}$ is probably due in part to its higher brightness compared to the LEECs with $\mathbf{8}$ or $\mathbf{9}\left(L_{\max }=15.4 \mathrm{~cd} \mathrm{~m}^{-2}\right.$ for $\mathbf{8}$, $16.1 \mathrm{~cd} \mathrm{~m}^{-2}$ for 9 and $37.0 \mathrm{~cd} \mathrm{~m}^{-2}$ for 10). Nevertheless, although these complexes are the most stable among blue-green LEECs, none of them come close to

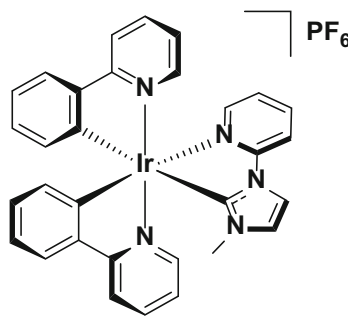

8

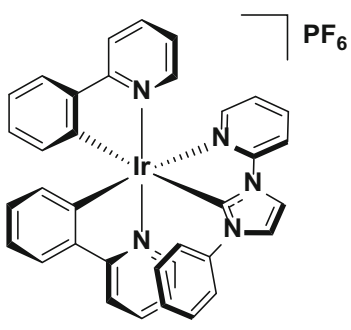

9

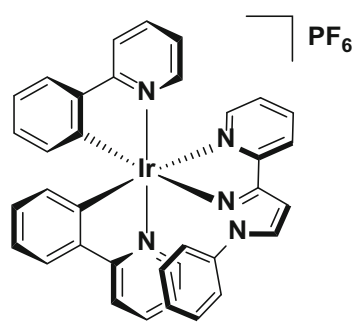

10

Fig. 9 Iridium complexes bearing NHC ancillary ligands 


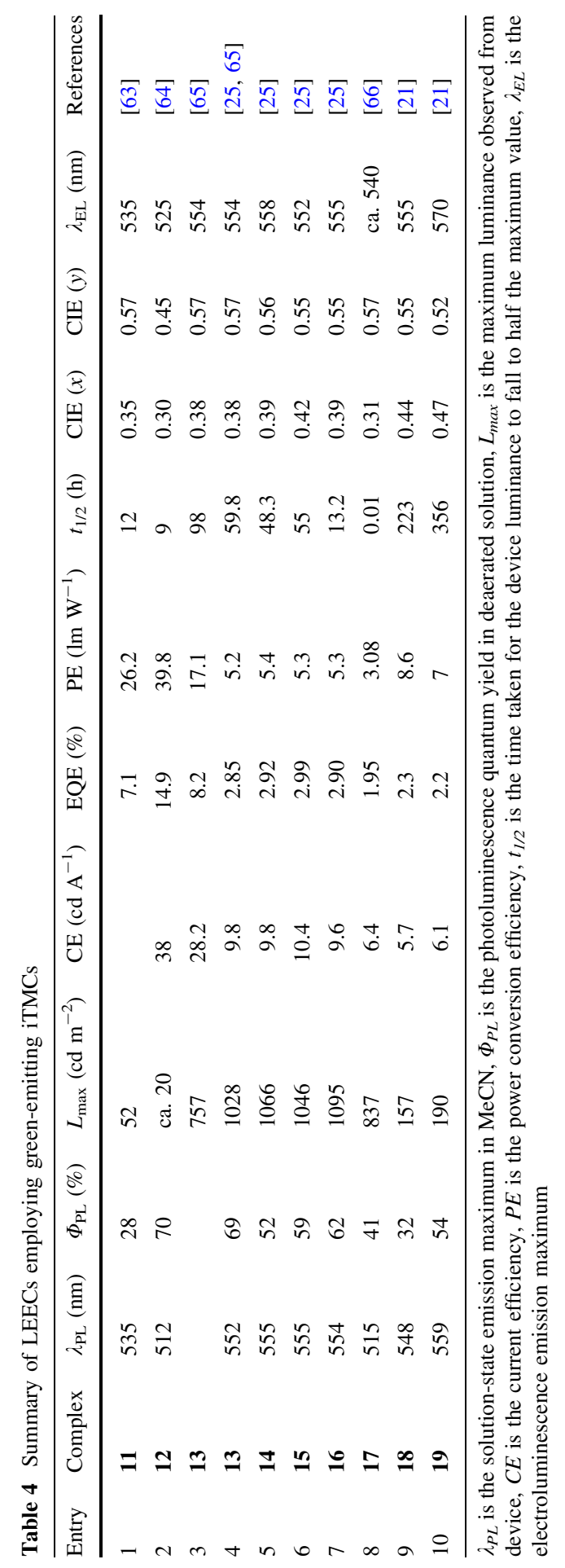


commercially relevant stability requirements or even to some of the stability metrics reported for yellow or orange devices (thousands of hours).

\section{Green}

Green emitters, like sky-blue emitters, have also been shown to achieve high efficiencies but relatively low stabilities. Many green-emitting complexes also contain fluorinated cyclometalating ligands, which certainly account for their shorter device lifetimes compared to yellow or orange LEECs. A summary of the emitters discussed in this section is given in Table 4.

\subsection{Efficiency}

Most LEECs reported, even now, employ constant voltage-driving methods as a means of powering the device. Such a method results in generally slow turn-on times, but good performance metrics in terms of brightness and efficiency have been reported. Two of the best performing LEECs were reported employing complexes $\mathbf{1 1}$ and 12. The crucial design feature of $\mathbf{1 1}$ is that it contains a bulky 4,5-diaza- $9,9^{\prime}$ spirobifluorene ancillary ligand [63]. The bulk of this ligand ensures that intermolecular quenching in the solid state is minimized. The photoluminescence quantum yield in the neat film $\left(\Phi_{\mathrm{PL}}=31 \%\right)$ is in fact not measurably different compared to the quantum yield in solution $\left(\Phi_{\mathrm{PL}}=28 \%\right)$. Ultimately, it is this high neat film quantum yield that accounts for the very good device efficiency $\left(\mathrm{EQE}=7.1 \% ; \mathrm{PE}=26.2 \mathrm{~lm} \mathrm{~W}^{-1}\right)$. Similarly, complex 12 employs the bulky $4,4^{\prime}$-di-tert-butyl-2,2'-bipyridine ancillary ligand. In this case, the quantum yields are even higher $\left(\Phi_{\mathrm{PL}}=70 \%\right.$ in solution and $72 \%$ in the film used for the device), giving device efficiencies that are extraordinarily high (EQE $=14.9 \%$ ) [64].

Both of these devices are driven at a constant voltage $(2.8 \mathrm{~V}$ for $\mathbf{1 1}$ and $3.0 \mathrm{~V}$ for 12). This driving method leads to some drawbacks, including long device turn-on times $\left(t_{\mathrm{on}}=1.5 \mathrm{~h}\right.$ for $\mathbf{1 1}$ and $0.8 \mathrm{~h}$ for 12) and also relatively poor stability $\left(t_{1 / 2}=12 \mathrm{~h}\right.$ for $\mathbf{1 1}$ and $9 \mathrm{~h}$ for 12) for both devices. However, it is worth noting that a pulsed current LEEC (which will be elaborated on below) based on $\mathbf{1 2}$ has been

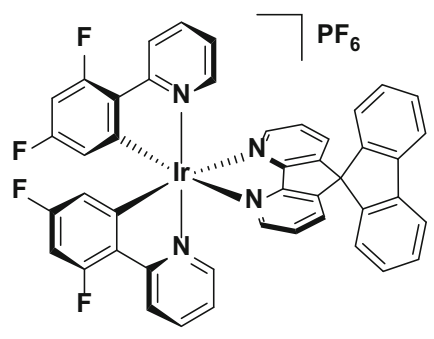

11

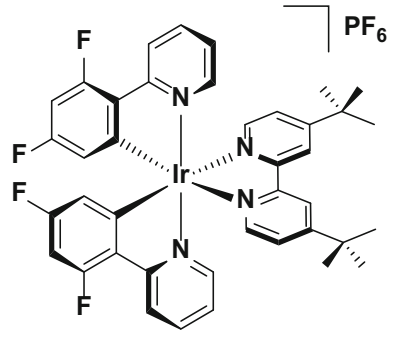

12

Fig. 10 Efficient green-emitting devices based on constant voltage-driving conditions 
reported, demonstrating much lower efficiencies $(\mathrm{EQE}=2.83 \%)$ than reported under constant voltage [17] (Fig. 10).

In recent years an alternative driving method has become prevalent for operating these devices. Using a pulsed current driving method, high device efficiencies are also possible, but not at the expense of the stability or turn-on times of the devices. Arguably the champion green LEEC published to date is based on complex 13, which uses a pulsed-current driving method to operate the device [65]. In the report, the authors explored driving the devices under a variety of different conditions, including varying the duty cycles from $25 \%$ to $100 \%$ (the latter of which correlates to operation under constant current) and also the average pulsed current density, from 18.75 to $150 \mathrm{~A} \mathrm{~m}^{-2}$. After much optimization, it was found that a $75 \%$ duty cycle with a pulsed-current density of $25 \mathrm{~A} \mathrm{~m}^{-2}$ led to the best overall device performance. Crucially, it was found that high device efficiencies $(\mathrm{EQE}=8.2 \%$, $\mathrm{CE}=28.2 \mathrm{~cd} \mathrm{~A}^{-1}, \mathrm{PE}=17.1 \mathrm{~lm} \mathrm{~W}^{-1}$ ) were possible, without adversely affecting the stability $\left(t_{1 / 2}=98 \mathrm{~h}\right)$ or the turn on time $\left(t_{\mathrm{on}}=0.2 \mathrm{~s}\right)$. Indeed, these metrics make this LEEC the best overall performer, certainly when comparing the turn-on times and stabilities of the constant voltage LEECs employing 11 and $\mathbf{1 2 .}$

\subsection{Stability}

Complex 13 has also been reported as part of a larger study into the stability of iridium complexes bearing fluorinated $\mathrm{C}^{\wedge} \mathrm{N}$ ligands.[16a] As identified in Sect. 3, such complexes are expected to be unstable, due to the reactivity of such aromatic rings bearing fluorine substituents. To unequivocally study this, Baranoff et al. synthesized complexes 13-16, and studied their performance in the LEEC. All four complexes were designed to have similar photophysical properties $\left(\lambda_{\mathrm{PL}}=552-555 \mathrm{~nm}, \quad \Phi_{\mathrm{PL}}=52-69 \%\right)$ and similar device properties $\left(\mathrm{EQE}=2.85-2.99 \%, L_{\max }=1028-1095 \mathrm{~cd} \mathrm{~m}^{-2}\right)$, such that the stability data would be directly comparable. They demonstrated that complex 16, bearing four fluorine atoms, shows greatly reduced device lifetimes $\left(t_{1 / 2}=13.2 \mathrm{~h}\right)$ compared with the other three complexes $\left(t_{1 / 2}=48.3-59.8 \mathrm{~h}\right.$ for complexes 13-15). The device lifetimes for complexes 13-15 are by comparison rather long for green emitters; indeed, only $\mathbf{1 8}$ and $\mathbf{1 9}$ are longer lived green emitters in the device (Fig. 11).
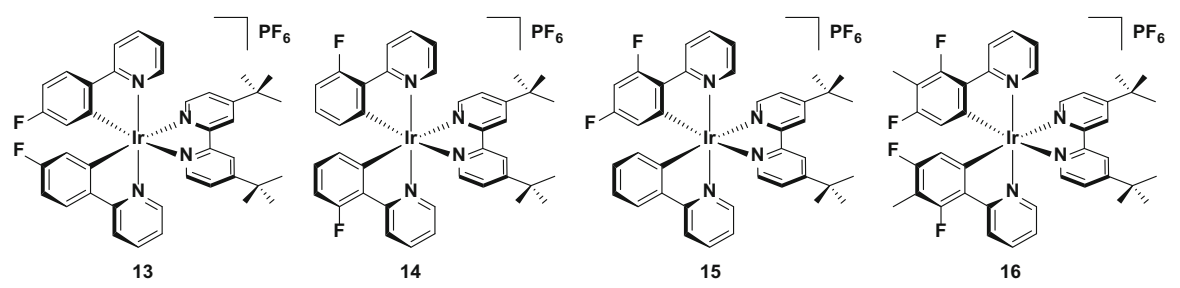

Fig. 11 Multiply fluorinated green-emitting iridium complexes. The tetra-fluorinated complex displays much faster device degradation than the bis-fluorinated complexes 
To address issues with the stability of fluorine-containing iridium complexes, there has been interest in developing so-called fluorine-free ligands that are capable of achieving blue-shifted emission. Complex 17, for example, was one of a number of complexes reported utilizing a 2,3'-bipyridine as the cyclometalating ligand to achieve a similar effect as that of the dFppy ligand, with the non-coordinating nitrogen acting to inductively withdraw electron density away from the metal centre, thereby stabilizing the HOMO energy and blue-shifting the emission as a result [66]. Although the stability of the devices based these emitters was not significantly improved $\left(t_{1 / 2}=0.01-2.5 \mathrm{~h}\right)$ it is worth noting that the CIE coordinates of 17 (CIE: 0.31, 0.57) are the closest to pure green (CIE 0.30, 0.60) that have been reported so far.

Complexes 18 and 19 provide a good comparison with 13. The electroluminescence of these complexes is only slightly red-shifted (CIE 0.44, 0.55 for $\mathbf{1 8}$ and $0.47,0.52$ for $19 ; \lambda_{\mathrm{EL}}=555 \mathrm{~nm}$ for 18 and $570 \mathrm{~nm}$ for 19) compared to 13 (CIE $\left.0.38,0.57, \lambda_{\mathrm{EL}}=554 \mathrm{~nm}\right)$, but they show greatly improved stabilities $\left(t_{1 / 2}=98 \mathrm{~h}\right.$ for $\mathbf{1 3}, 223 \mathrm{~h}$ for $\mathbf{1 8}$ and $356 \mathrm{~h}$ for 19). This is attributed to the methyl groups in the ortho- position with respect to the pyridyl nitrogens, which act in a similar fashion to the intramolecularly $\pi$-stacking phenyl rings for $\mathbf{9}$ and 10. It is plausible also that the lack of fluorine substituents appended to complexes $\mathbf{1 8}$ and $\mathbf{1 9}$ also adds to their stability in the device (Fig. 12).

\section{Yellow/orange}

Moving from green emitters to yellow/orange leads to a pattern becoming apparent: as the color of the device shifts from blue to yellow the efficiency of the devices generally decreases, but the stability improves. Indeed, emitters of these colors surpass all others in terms of stability, with the most stable devices reported to date emitting in this color regime (Table 5).

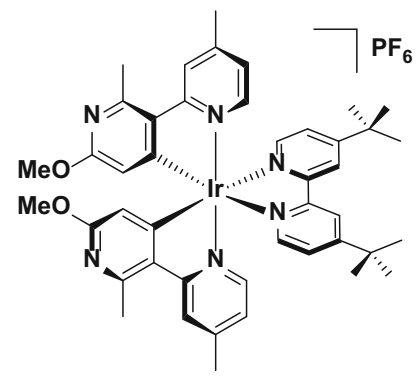

17

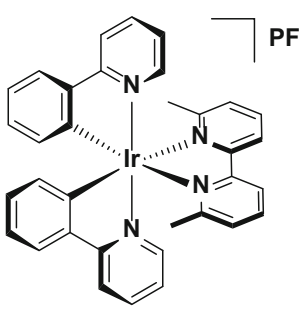

18

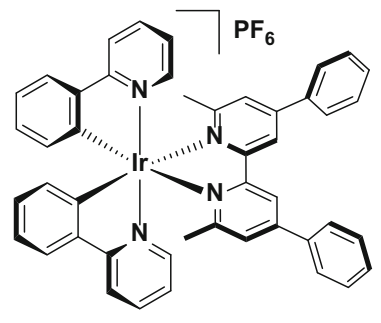

19

Fig. 12 High stability green emitters 


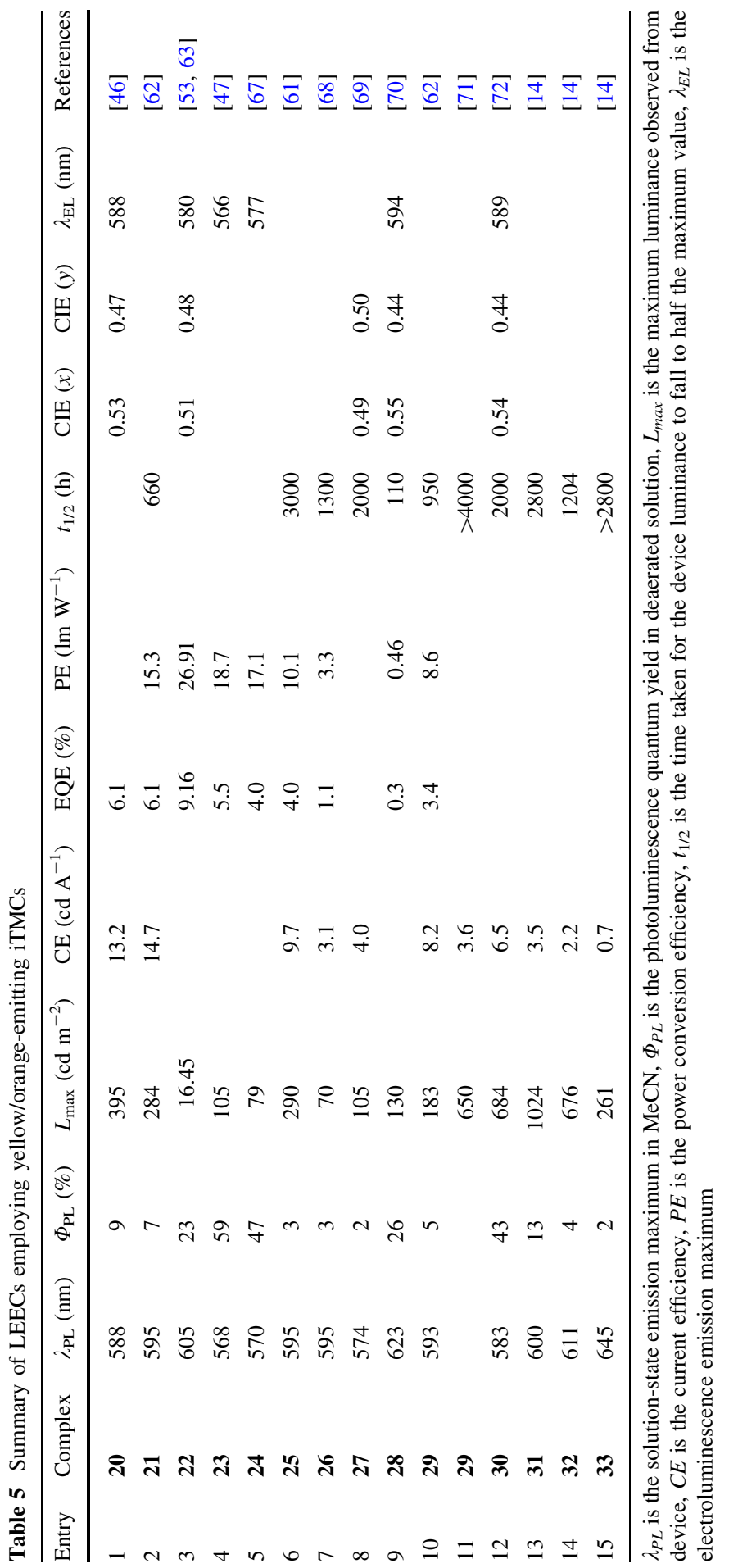




\subsection{Efficiency}

Efficiencies reported for yellow/orange LEECs tend not to be as high as for green LEECs, although several examples of complexes with comparable efficiencies have been reported. For example, the external quantum efficiencies reported for the devices using $\mathbf{2 0}$ and $\mathbf{2 1}$ are two of the highest $(\mathrm{EQE}=6.1 \%$ for both $\mathbf{2 0}$ and $\mathbf{2 1}$ ) reported for this color to date [46, 62]. The origin of the high efficiency for $\mathbf{2 0}$ is not explained. In solution this complex is not especially emissive $\left(\Phi_{\mathrm{PL}}=9 \%\right.$ in $\mathrm{MeCN}$ ) and no thin film PL data is reported. Complex 21 is also poorly emissive in solution $\left(\Phi_{\mathrm{PL}}=7 \%\right.$ in $\left.\mathrm{MeCN}\right)$ but in this instance the value reported for the $\Phi_{\mathrm{PL}}$ in the film is much higher $\left(\Phi_{\mathrm{PL}}=47 \%\right.$ in a film of iridium complex and [BMIM] $\left[\mathrm{PF}_{6}\right]$ in 4:1 molar ratio), which accounts for the good device performance. As with other complexes previously discussed, the performance of $\mathbf{2 1}$ in the device is attributed to the presence of the bulky hydrophobic substituents on the complex, which contribute to decreased quenching of the excitons formed in the device. An added benefit of the substitutions on the ancillary bipyridine ligand is that they improve the stability of the emitter in the device, with a very good device lifetime compared to many other LEECs reported in the literature $\left(t_{1 / 2}=660 \mathrm{~h}\right)$. This result is in contrast with the LEECs using complexes $\mathbf{9}$ and 10, wherein the shielding of the iridium centre by the intramolecular $\pi$-stacking interaction was mitigated somewhat by the use of five-membered pyrazole and imidazolium rings (Fig. 13).

The highest efficiency yellow/orange device reported to date is complex $\mathbf{2 2}$, which is the fluorine-free analogue of complex 11, using the same 4,5-diaza-9,9'spirobifluorene as the diimine ligand [53,63]. Steric bulk of this ligand remains an important factor in preventing intermolecular quenching in the device by increasing the spacing between the chromophores, leading to a reasonably bright emitter in solution $\left(\Phi_{\mathrm{PL}}=23 \%\right)$ and solid state $\left(\Phi_{\mathrm{PL}}=33 \%\right.$ in the 'LEEC' film containing the iridium complex and $[\mathrm{BMIM}]\left[\mathrm{PF}_{6}\right]$ in a 1.3:1.0 molar ratio). Its initial device efficiency was reported to be $7.1 \%$ using a simple LEEC architecture [ITO/ Ir:[BMIM][PF 6 (1.3:1.0 molar ratio)/Ag]. However, studies on improving the carrier injection efficiency of the device have since led to a record quantum efficiency $(\mathrm{EQE}=9.16 \%)$ reported for a yellow/orange device, based on a related device architecture [ITO/PEDOT:PSS/Ir:[BMIM] $\left[\mathrm{PF}_{6}\right] / \mathrm{Ag}$. This improved

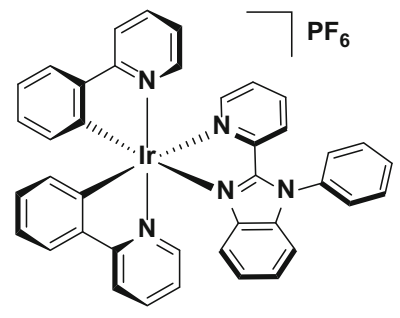

20

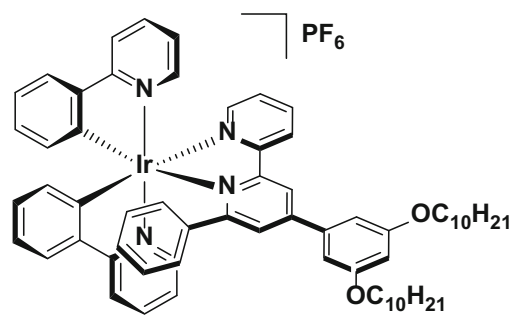

21

Fig. 13 Yellow/orange emitters showing high device efficiencies 
performance is likely to be due to the fact that $\mathbf{2 2}$ has preferred electron-transporting characteristics [53], and thus PEDOT:PSS, which is effective as a hole injecting layer, helps to balance charge transport in the device.

It is curious to note however, that analogues of $\mathbf{2 2}$, using the same diazafluorenyltype ligand (23 and $\mathbf{2 4})$ are in fact brighter in solution than $\mathbf{2 2}\left(\Phi_{\mathrm{PL}}=59 \%\right.$ and $47 \%$, respectively), but display poorer performance in the device [67]. These emitters were designed to explore strategies for improving the turn-on time of the LEEC, with the charged groups appended to $\mathbf{2 4}$ anticipated to increase the rate of ion separation in the emissive layer similar to that previously demonstrated by Zysman-Colman et al. [73]. and thus more quickly lower the barrier to charge injection into the device. This effect is achieved $\left(t_{\text {on }}=1.1 \mathrm{~h}\right.$ for 23 and $0.2 \mathrm{~h}$ for 24) but at the detriment of the performance of the emitter in the device $(\mathrm{EQE}=5.5 \%$ for $\mathbf{2 3}$ and $4.0 \%$ for $\mathbf{2 4})$, suggesting that even minor changes to functionality peripheral to the electronics of the emitter can nevertheless have a significant effect on the efficiency (Fig. 14).

\subsection{Stability}

Complex 25 is the first example reported of a complex containing the intramolecular $\pi$-stacking motif alluded to previously. Within $\mathbf{2 5}$, there is a short centroid-tocentroid distance of $3.48 \AA$ between the phenyl ring on the bpy and one of the cyclometalating phenyl rings. This tight interaction maintains the structural integrity of the inner coordination sphere, even when the anti-bonding e.g., orbitals of the MC states are populated, and thus inhibits potential nucleophiles from coordinating to the metal centre upon population of the ${ }^{3} \mathrm{MC}$ states. The devices reporting this emitter were operated under constant voltage and two values have been reported for the device lifetime based on this emitter $\left(t_{1 / 2}=\right.$ ca. $1300 \mathrm{~h}[36,62,68]$ or $3000 \mathrm{~h}$ [61]), with the longer value resulting from operating the device with a pre-biasing method (Fig. 15).

Although the intramolecular $\pi$-stack is an effective strategy for increasing device stability, it does have limits: complex 26, with two incorporated $\pi$-stacking phenyl rings on the ancillary ligand results in poorer device performance compared to that with 25 [68]. Devices based on 25 and 26 both show long lifetimes $\left(t_{1 / 2}=1300 \mathrm{~h}\right.$ for 25 and 26). However, the luminance values of $25\left(L_{\max }=110 \mathrm{~cd} \mathrm{~m}^{-2}\right)$ are higher than for $\mathbf{2 6}\left(L_{\max }=70 \mathrm{~cd} \mathrm{~m}^{-2}\right)$. Devices with different luminance levels are not necessarily comparable in terms of stability, since brighter devices intrinsically

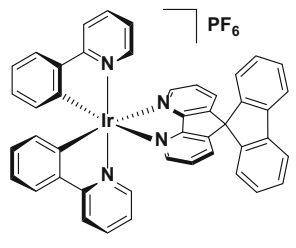

22

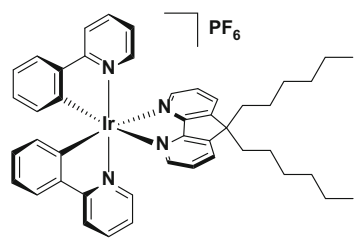

23

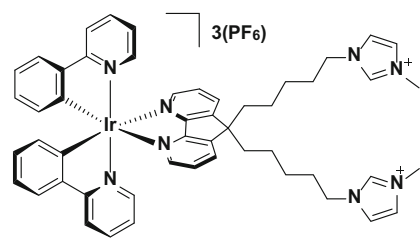

24

Fig. 14 High efficiency yellow/orange emitter (22) and related complexes (23 and 24) 


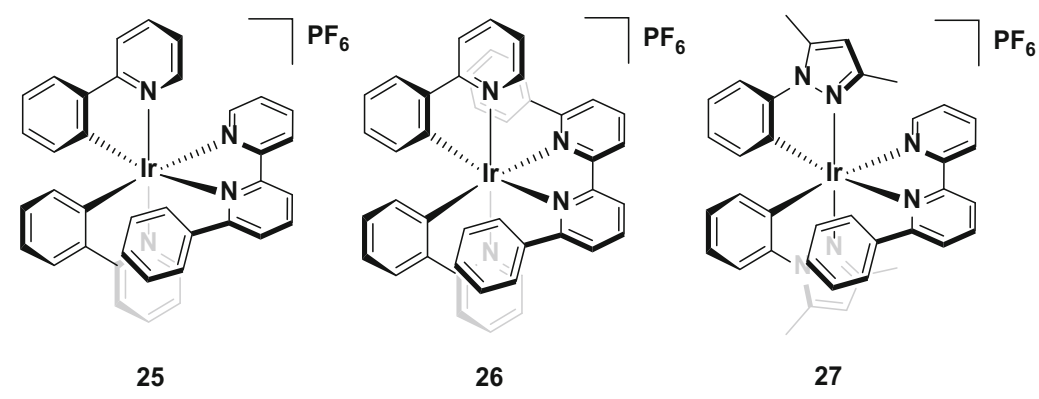

Fig. 15 Champion stable LEECs operated at constant voltage

degrade more quickly. Thus, to compare devices of different luminance levels it has been argued that considering the total photon flux emitted from the device once the luminance reaches $1 / 5$ of the maximum value, $E_{t_{1 / 5}}$, is a more accurate assessment of its stability. In this instance, 25 showed higher $E_{t_{1 / 5}}$ values $(13.6 \mathrm{~J})$ than 26 $(6.9 \mathrm{~J})$, and thus it was concluded to be the more stable emitter. It was rationalized that the although the additional $\pi$-stacking ring further shields the metal centre, in order to maximize the dual $\pi$-stacking interaction there is a distortion of the inner coordination the sphere of the complex. This distortion in turn makes the MC states more thermally accessible, thus promoting exciton quenching and making the complex more susceptible to degradation reactions in the device.

An alternative strategy designed to protect the iridium from adventitious attack of small molecule nucleophiles is shown for complex 27 [69]. Here, the methyl groups appended to the pyrazole rings add an additional steric shield to the metal centre similar to complexes 18 and 19. This strategy confers excellent stability to the LEEC with the device with 27 showing higher lifetimes $\left(t_{1 / 2}=2000 \mathrm{~h}\right)$ than that reported using 25 as the reference emitter $\left(t_{1 / 2}=1290 \mathrm{~h}\right)$ (Fig. 16).

In general, hydrophobic substituents appear to improve the stability of the emitter in the device. For example, the phenyl rings on the 5,5'-positions of the ancillary ligand of complex $\mathbf{2 8}$ do not form an intramolecular $\pi$-stacking motif. Nevertheless, the hydrophobicity of these rings appear to confer good stability to the device, with

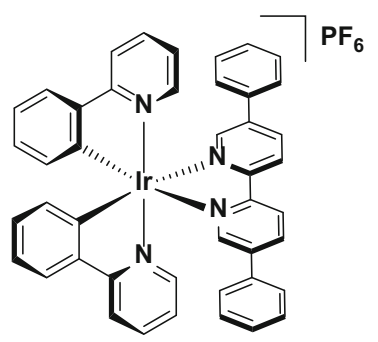

28

Fig. 16 Stable LEEC based on a hydrophobic iridium complex 
good brightness $\left(L_{\max }=130 \mathrm{~cd} \mathrm{~m}^{-2}\right)$ and a reasonable device lifetime $\left(t_{1 / 2}=110 \mathrm{~h}\right)$ [70] without impacting greatly the emission color compared to $\mathbf{1}$.

Given the aforementioned benefits of pulsed current LEECs, it is plausible that pulsed current LEECs based on complexes 25-28 would perform even better. Complex 29, which is the methoxy analogue of 21, is a good example of the contrasting performances of an emitter in a LEEC under constant voltage and pulsed current conditions. Under constant driving voltage, the device was reported to show good stability $\left(t_{1 / 2}=950 \mathrm{~h}\right)$ [62], but this is well below the value reported for this emitter under pulsed current conditions $\left(t_{1 / 2}=4000 \mathrm{~h}\right)$ [71]. Indeed, this latter lifetime is the longest reported for any iridium-based LEEC to date. The long lifetime in the device is coupled with higher brightness $\left(L_{\max }=650 \mathrm{~cd} \mathrm{~m}^{-2}\right.$ under pulsed current vs. $183 \mathrm{~cd} \mathrm{~m}^{-2}$ under constant voltage), although the efficiency under constant voltage is higher $\left(\mathrm{CE}=8.2 \mathrm{~cd} \mathrm{~A}^{-1}\right.$ under constant voltage versus $3.6 \mathrm{~cd} \mathrm{~A}^{-1}$ for pulsed current).

The merits of the pulsed current driving method are exemplified by the device with 30. To the best of our knowledge, this complex is the only emitter reported with a device lifetime of greater than one thousand hours $\left(t_{1 / 2}=2000 \mathrm{~h}\right)$ that does not have an intramolecular $\pi$-stacking motif. The device with this complex also shows a higher efficiency than that with $29\left(\mathrm{CE}=6.5 \mathrm{~cd} \mathrm{~A}^{-1}\right)$ under pulsed current driving [72] (Fig. 17).

Finally, complex 31 represents arguably the most stable emitter reported to date [14]. The values reported for complexes 31-33 are from operating the devices at an exceptionally high current density of $300 \mathrm{~A} \mathrm{~m}^{-2}$. Typically, pulsed-current LEECs are operated at average current densities of 50-100 $\mathrm{A} \mathrm{m}^{-2}$ (29 was operated at an average of $185 \mathrm{~A} \mathrm{~m}^{-2}$ and 30 at $100 \mathrm{~A} \mathrm{~m}^{-2}$ ); however, at these current densities no discernible degradation of the devices could be observed and thus a much higher average current density was required. The high stability of the device at these current densities for all three complexes $\left(t_{1 / 2}=2800 \mathrm{~h}\right.$ for 31, $1204 \mathrm{~h}$ for 32, and $>2800 \mathrm{~h}$ for $\mathbf{3 3}$ ) is attributed to the silver-assisted synthesis of these complexes to ensure they are free of chloride impurities, which as discussed above, are detrimental to the performance of these complexes in the device.

Since no $E_{t 1 / 5}$ values are reported it is difficult to discern which of the three complexes is the most stable; however, the much higher luminance value for $\mathbf{3 1}$

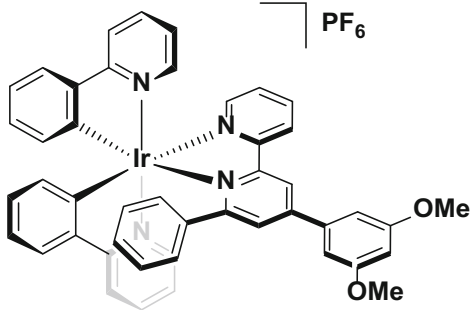

29

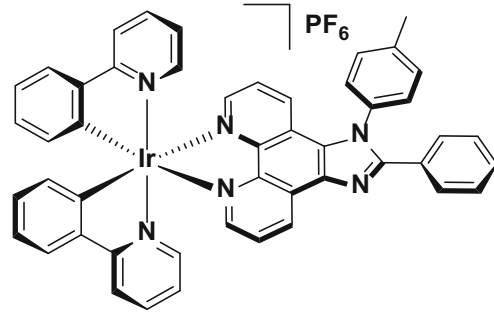

30

Fig. 17 High stability emitters operated under pulsed-current conditions 
$\left(L_{\max }=1024 \mathrm{~cd} \mathrm{~m}^{-2}\right) \quad$ compared with $32 \quad\left(L_{\max }=676 \mathrm{~cd} \mathrm{~m}^{-2}\right)$ and $\mathbf{3 3}$ $\left(L_{\max }=261 \mathrm{~cd} \mathrm{~m}^{-2}\right)$ suggest that it is the champion emitter in terms of device stability. It is surprising however, that $\mathbf{3 1}$ is the simplest of these structures, with no intramolecular $\pi$-stacking motif. These results illustrate that there are still challenges for correlating the structure of an emitter to its performance in the device (Fig. 18).

\section{Red}

Although the challenge of designing blue emitters is still the greatest for LEECs (no LEEC so far has been reported to even achieve deep-blue emission, let alone with good device performance), only a small number of LEECs have been reported to have CIE coordinates close to the ideal red value (CIE 0.66, 0.33) and, like the blue LEECs reported to date, these devices all show poorer stability compared with yellow/orange LEECs (Table 6).

\subsection{Efficiency}

Although heterocycles such as pyrazoles and imidazoles are rarely used for red emission (due to their strong $\sigma$-donating character and their tendency to induce blue-shifting in the emission compared with pyridyl rings), two of the best redemitting devices nevertheless utilize such heterocycles. Complex 34 utilizes a phenylpyrazole-type cyclometalating ligand but compensates for its blue-shifting effect by incorporation of the highly conjugated $2,2^{\prime}$-biquinoline ancillary ligand to red shift the emission [33]. Similarly, the LUMO destabilizing capabilities of the imidazole ring contained within the ancillary ligand of $\mathbf{3 5}$ are also compensated by the annelated benzene to form the benzimidazole and by the appended quinoline ring [46]. Both of these complexes are red emitters $\left(\lambda_{\mathrm{PL}}=624 \mathrm{~nm}\right.$ for 34 and $627 \mathrm{~nm}$ for 35$)$ in MeCN solution but they are only poorly emissive ( $\Phi_{\mathrm{PL}}=0.68 \%$ for 34 and $3 \%$ for $\mathbf{3 5}$ ), presumably as a function of the energy gap law. Photoluminescence quantum yield data in the solid state is not reported for either of these emitters so it is not possible to correlate these to the device performances. However, high efficiencies are reported for both devices, particularly the device

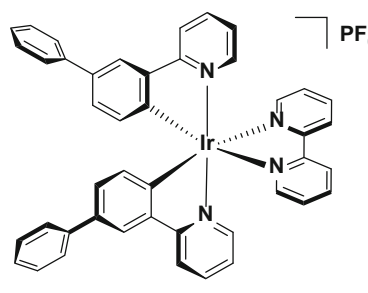

31

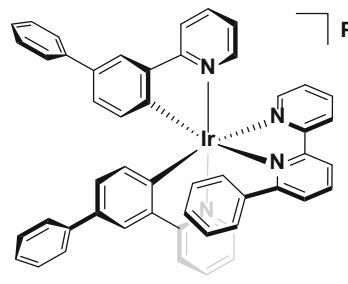

32

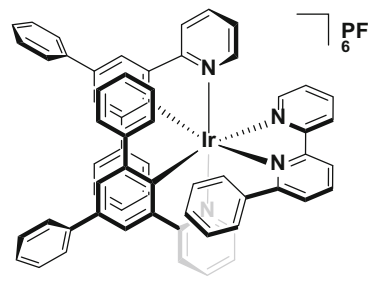

33

Fig. 18 Champion-pulsed current LEEC for stability (31) and related analogues (32 and 33) 


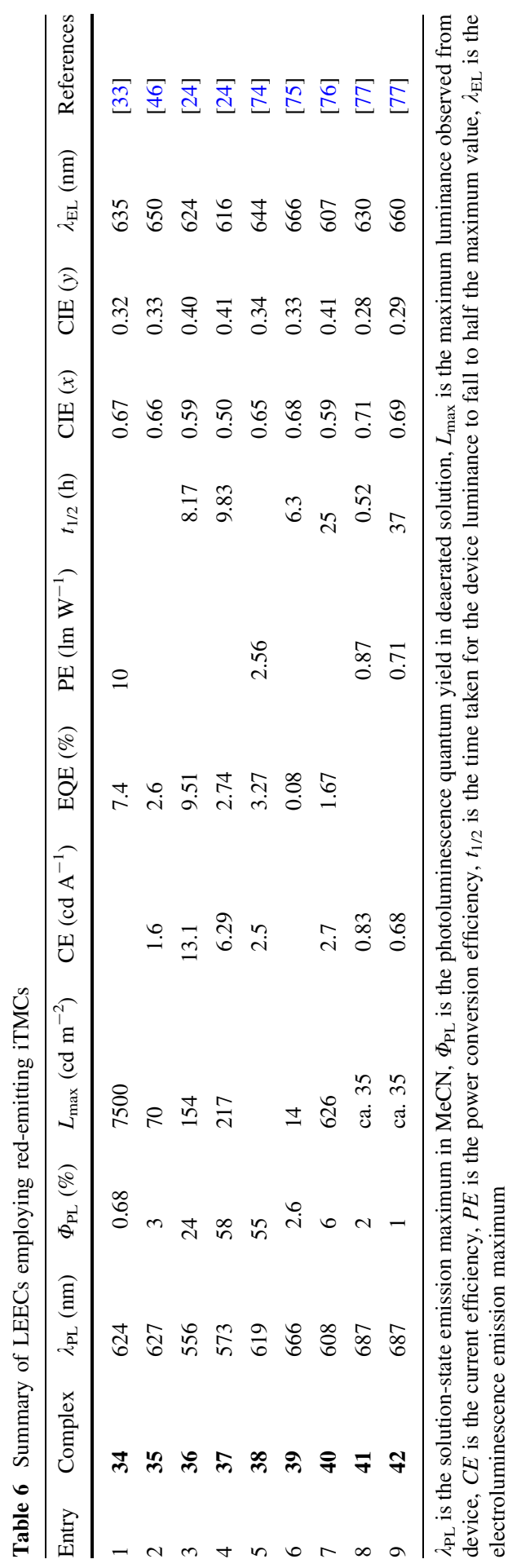


based on 34, $(\mathrm{EQE}=7.4 \%$ for $\mathbf{3 4}$ and $2.6 \%$ for 35), making them among the best red devices reported to date. In addition, the color of both devices essentially coincides with the pure red CIE coordinate (CIE 0.67, 0.32 for 34 and $0.66,0.33$ for 35 (Fig. 19).

One of the intrinsic issues with blue emitters is that the emission is frequently red-shifted in the device. For red emitters, this feature can act as an advantage, exemplified by complexes 36 and 37 [24]. In solution these complexes emit yellow light $\left(\lambda_{\mathrm{PL}}=573 \mathrm{~nm}\right.$ for 36 and $556 \mathrm{~nm}$ for 37), but in neat film $\left(\lambda_{\mathrm{PL}}=627 \mathrm{~nm}\right.$ for 36 and $625 \mathrm{~nm}$ for 37$)$ and in the device $\left(\lambda_{\mathrm{EL}}=624 \mathrm{~nm}\right.$ for 36 and $616 \mathrm{~nm}$ for 37) the emission is strongly red-shifted. The authors attribute this red shift to the possible formation of excimers in the condensed phase, due to strong $\pi-\pi$ intermolecular stacking interactions observed in the crystal structures of $\mathbf{3 6}$ and $\mathbf{3 7 .}$ Crucially, this red shift in emission observed in the LEEC is accompanied with impressive device performance, particularly for 36, which shows the highest device efficiency of any red or yellow/orange device reported to date $(\mathrm{EQE}=9.51 \%$ for 36 and $2.74 \%$ for 37). This high efficiency certainly qualifies $\mathbf{3 6}$ as the champion red-emitting device reported to date. However, it is worth noting that the CIE coordinates of these devices (CIE $0.59,0.40$ for 36 and $0.50,0.41$ for 37) are blueshifted compared to the pure red CIE coordinates (CIE: $0.66,0.33$ ) required for RGB color coordinates (Fig. 20).

Finally, complex 38 is an interesting red emitter [74]. The extended conjugation of the perylenediimide unit was used to achieve deep-red emission, while also functioning as an electron-transporting moiety to balance the hole conducting capabilities of the iridium component. It was found that the iridium essentially does not contribute to the photophysics of the compound. The short emission lifetime $\left(\tau_{\mathrm{e}}=3.0 \mathrm{~ns}\right)$ and high quantum yield $\left(\Phi_{\mathrm{PL}}=55 \%\right)$ for a red emitter $\left(\lambda_{\mathrm{PL}}=619 \mathrm{~nm}\right)$ point instead towards fluorescence directly from the perylenediimide chromophore, an assignment supported by theoretical calculations that implicated only the perylenediimide unit in the electronics of the HOMO or LUMO. Thus, the iridium in this case acts only as an appended charged unit to enable this complex to function in the LEEC.

Crucially, the short emission lifetime is suggested to help in circumventing nonradiative quenching pathways in which typical triplet emitters are susceptible,

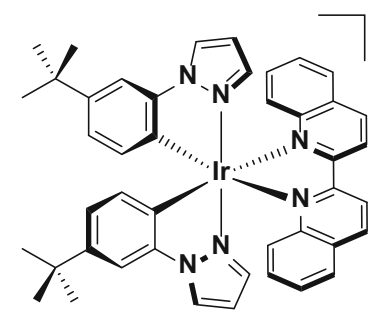

34

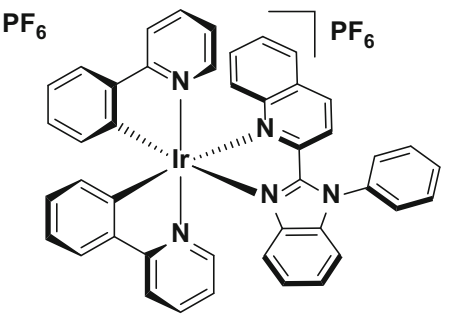

35

Fig. 19 High efficiency, red-emitting iridium complexes 
Fig. 20 Champion red-emitting device (36) and its analogue (37)

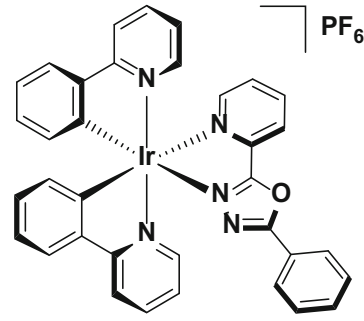

36

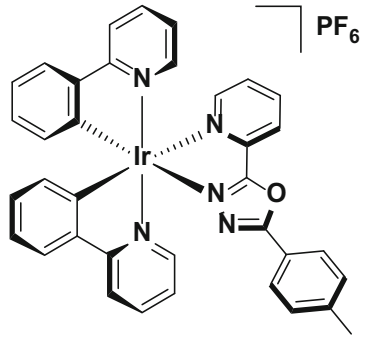

37

leading to a good efficiency $(\mathrm{EQE}=3.27 \%)$ for a red-emitting device (CIE 0.65, 0.34). Although a useful feature, it is unclear if this compound is purely a singlet emitter, or whether it is in fact harvesting triplets as well, an important feature of typical phosphorescent iridium complexes. In this instance, it is possible that this strategy is in fact wasting the triplets generated in the emissive layer, defeating the object of utilizing an iridium-based material in the first place (Fig. 21).

\subsection{Stability}

Complex 39 employs a 2,5-dipyridyl(pyrazine) ancillary ligand which, demonstrating the opposite trend to complex 17, shows red-shifted emission as a result of the electron-withdrawing nature of the non-coordinating nitrogen on the pyrazine ring [75]. Thus, in this instance, the LUMO is strongly stabilized. Further narrowing of the HOMO-LUMO gap comes by way of the non-coordinating pyridyl ring, which extends the conjugation on the ancillary ligand, red-shifting the emission further, both in solution $\left(\lambda_{\mathrm{PL}}=666 \mathrm{~nm}\right)$ and the device $\left(\mathrm{CIE} 0.68,0.33 ; \lambda_{\mathrm{EL}}=666 \mathrm{~nm}\right)$. Although the efficiency of the device is low $(\mathrm{EQE}=0.08 \%)$, the lifetime

Fig. 21 Deep-red-emitting iridium complex with good device efficiency

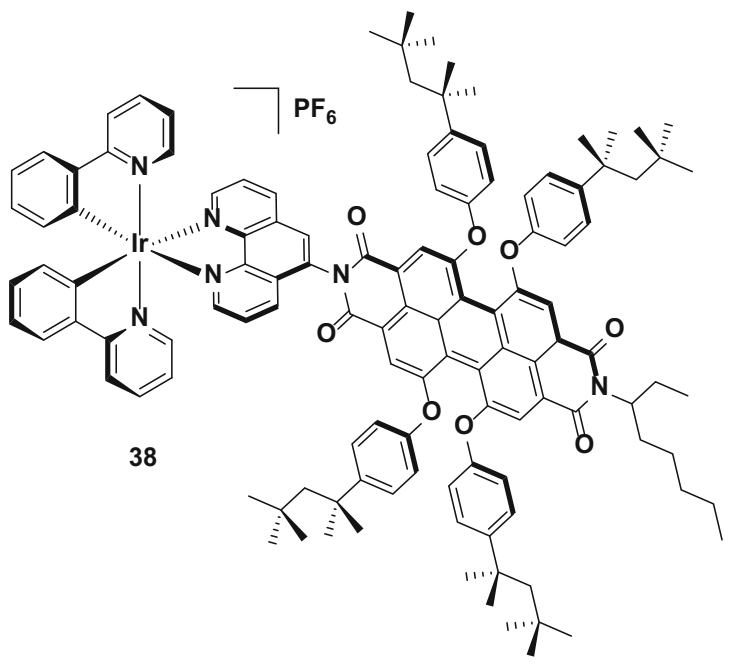


$\left(t_{1 / 2}=6.3 \mathrm{~h}\right)$ is rather long for a deep-red-emitting device. As with the examples below, much shorter device lifetimes compared with yellow/orange seems to be a general feature of deep-red-emitting LEECs (Fig. 22).

A number of red emitting intramolecularly $\pi$-stacked complexes have been reported but few of them demonstrate any appreciable stability when compared to their yellow/orange analogues. Indeed, even in the case of the most stable of the redemitting complex bearing an intramolecularly $\pi$-stacking motif, 40, the device lifetime $\left(t_{1 / 2}=25 \mathrm{~h}\right)$ is still very short compared with many other devices employing intramolecularly $\pi$-stacked complexes [76]. Although the luminance levels for this device are good $\left(L_{\max }=626 \mathrm{~cd} \mathrm{~m}^{-2}\right)$, the yellow-emitting devices utilizing structurally related complexes $\mathbf{3 2}$ and $\mathbf{3 3}$ are brighter and of course significantly longer lived. Clearly the stability of deep-red emitters is still lagging some way behind other devices reported to date (Fig. 23).

An alternative strategy reported for improving the stability of this class of emitters is that shown in a comparative study between complexes 41 and 42 . By covalently tethering the emitter to a polymer backbone, it was suggested that this should lead to a more uniform distribution of the complex within the emissive layer, reducing aggregate formation and increasing the spatial distribution of the emitters within the device, thereby improving the stability. Indeed, this appears to be the case, with a significant enhancement in the device lifetime with $42\left(t_{1 / 2}=37 \mathrm{~h}\right)$ compared to the device with $41\left(t_{1 / 2}=0.52 \mathrm{~h}\right)$. Although in absolute terms the lifetime of $\mathbf{4 2}$ is still poor, it is nevertheless the longest of any red device (CIE 0.69, 0.29 ) reported to date, suggesting that this is a viable, underexplored strategy for improving the stability of the device, as well as highlighting similar challenges in achieving stable red LEECs as discussed for achieving stable blue LEECs (Fig. 24).

\section{White}

Given the paucity of charged blue emitters, examples of white LEECs in the literature are subsequently scarce. Such devices broadly fall into one of two categories: host-guest systems, where a blue emitting host material is doped with a red emitter, or a multi-stack device where multiple emissive layers are combined

Fig. 22 Iridium complex with good stability for a deep-red LEEC

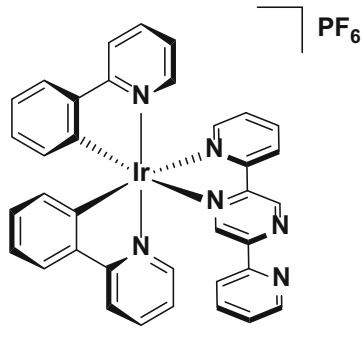


Fig. 23 Intramolecularly $\pi$ stacked deep-red-emitting iridium complex

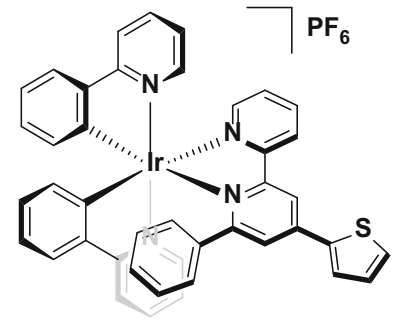

40

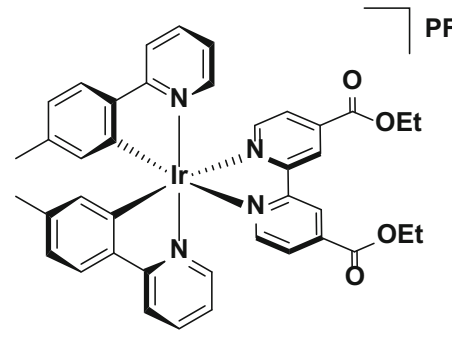

41

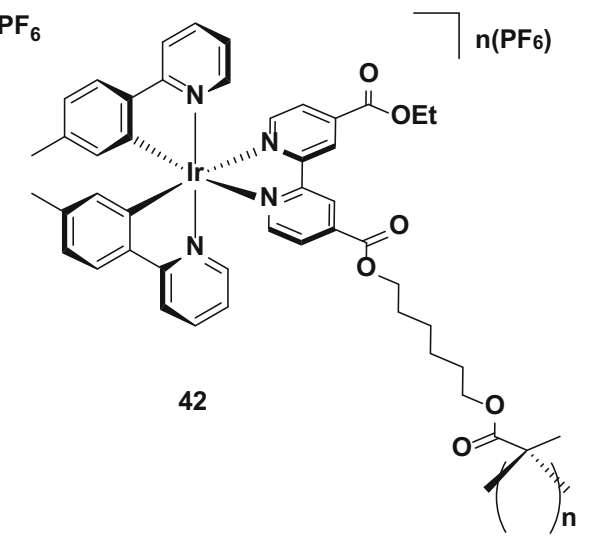

Fig. 24 Deep-red-emitting iridium complex and its corresponding polymer, which shows greatly enhanced stability

within a single device to achieve white light. Both families of devices will be discussed.

Although in these publications it is common for multiple configurations to be reported, we will discuss only the devices in a particular report that demonstrate CIE coordinates closest to the ideal white coordinate (CIE $0.33,0.33$ ), which is the ultimate goal of white LEECs, regardless of the performance of other devices in the report. Likewise, often these devices are operated at multiple biases, leading to significant changes in the color and the performance. Again we will consider only the driving voltage/current that achieves the 'whitest' emission. The values are summarized in Table 7.

\subsection{Host-guest LEECs}

The typical host-guest device is that based on 43, a blue-green emitter $\left(\lambda_{\mathrm{PL}}=491 \mathrm{~nm}\right.$ in the neat film), and 44, which is a deep-red emitter $\left(\lambda_{\mathrm{PL}}=672 \mathrm{~nm}\right.$ in the neat film) [78]. A small amount of 44 (0.4 wt \%) doped into 43 ensures a partial energy transfer (although not stated in this case, other references on white 


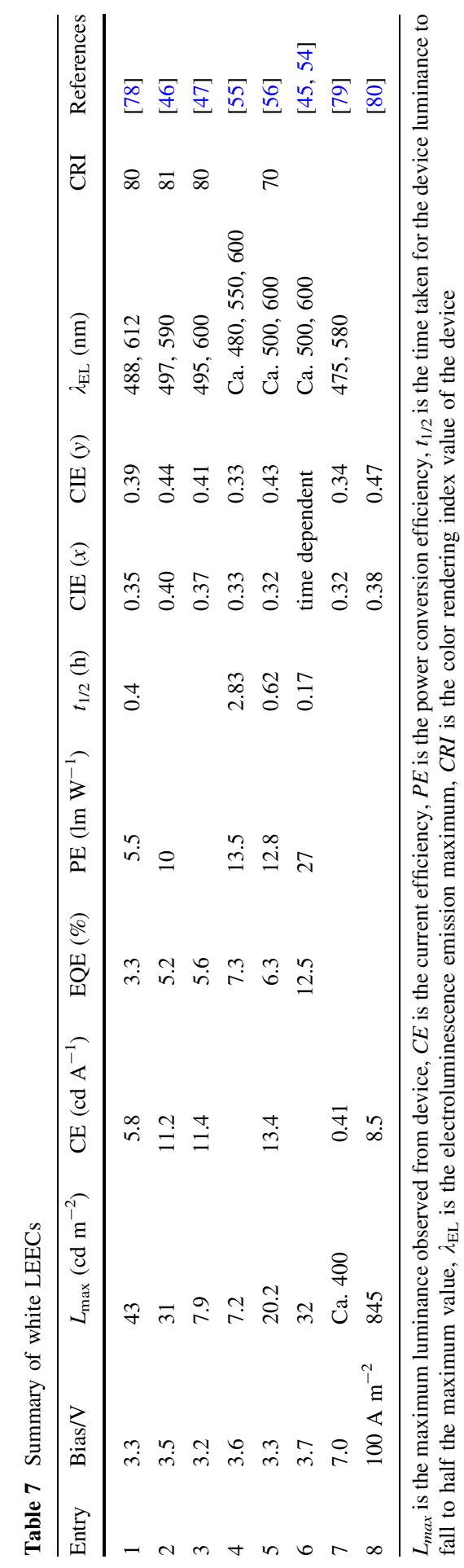


emitting LEECs describe this kind of energy transfer as Förster in nature) [55] from the excited blue host to the red emitting guest, resulting in emission from both chromophores, and giving white light as a result. Despite being the first reported example of a white light-emitting LEEC based on a host-guest system, the device showed decent efficiencies $(\mathrm{EQE}=3.3 \%)$, and crucially the color of the device was very close to the ideal white point (CIE 0.35. 0.39) (Fig. 25).

An improvement in the device performance of the white LEEC is documented in entries 2 and 3 in Table 7. A device utilizing $\mathbf{5}$ as the host and $\mathbf{3 5}$ as the guest (1: 0.002 molar ratio) achieved greatly improved efficiencies compared to entry 1 $\left(\mathrm{EQE}=5.2 \%, \mathrm{CE}=11.2 \mathrm{~cd} \mathrm{~A}^{-1}\right)$ [46], but with $\mathrm{CIE}$ coordinates that are modestly red-shifted (CIE: 0.40, 0.44) from the white point. Changing the host from 5 to 6 achieves a small increase in the efficiency $(\mathrm{EQE}=5.6 \%, \mathrm{CE}=11.4 \mathrm{~cd}$ $\mathrm{A}^{-1}$ ) and a slight blue shift in the CIE coordinates (CIE 0.37, 0.41) [47]. However, the brightness of the device based on $6\left(L_{\max }=7.9 \mathrm{~cd} \mathrm{~m}^{-2}\right)$ is greatly diminished compared with $5\left(L_{\max }=31 \mathrm{~cd} \mathrm{~m}^{-2}\right)$ (Fig. 26).

The most commonly used donor complex in host-guest LEEC systems is $\mathbf{4}$ and these devices tend to offer improved performance (entry 4). The guest in the LEEC need not be an iridium complex. For instance, the device shown in entry 4 has an EQE of $7.3 \%$ and employs a highly emissive $\left(\Phi_{\mathrm{PL}}=90 \%\right.$ in ethanol $)$ red-emitting dye compound, sulforhodamine 101 (SR 101) as an organic guest molecule. The high photoluminescence quantum yield of SR 101 is not typical of many redemitting systems; indeed, the previously discussed red-emitting phosphorescent dopants $35\left(\Phi_{\mathrm{PL}}=3 \%\right.$ in $\left.\mathrm{MeCN}\right)$ and $44\left(\Phi_{\mathrm{PL}}=20 \%\right.$ in $\left.\mathrm{MeCN}\right)$ show much lower quantum yields in solution than SR 101. The LEEC produces white light with CIE coordinates coinciding with the white point (CIE 0.33, 0.33). In addition, although the value is still short $\left(t_{1 / 2}=2.83 \mathrm{~h}\right)$ the device lifetime reported for this device is the longest for white LEECs reported to date [55] However, this is probably due at least in part to the very low luminance levels reported for this device $\left(L_{\max }=7.2 \mathrm{~cd} \mathrm{~m}^{-2}\right)$, particularly compared with the devices shown in entries 1 and 2 (Fig. 27).

Taking the doping strategy further, Su and co-workers[38c] have demonstrated that these LEECs can be 'double-doped', with one dopant providing the red-light component required for white light and the other dopant acting to improve charge transport in the emissive layer, as demonstrated by entry 5. In this case, complex 22

Fig. 25 Host-guest LEEC containing 43 as the blue/green host component and $\mathbf{4 4}$ as the red dopant. Device: ITO/43 (80.5 wt \%), 44 (0.4 wt \%), [BMIM] $\left[\mathrm{PF}_{6}\right](19.1 \mathrm{wt} \%) / \mathrm{Ag}$, entry 1

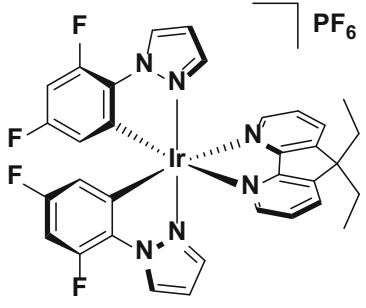

43

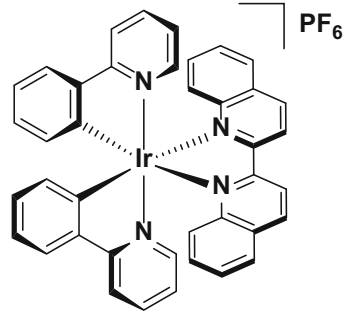

44 


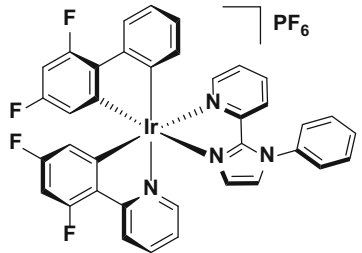

5

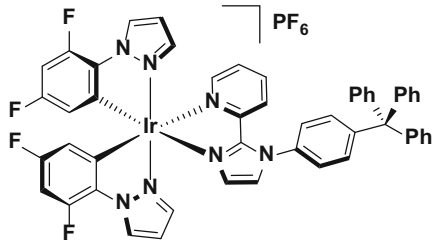

6

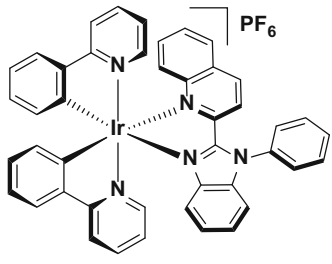

35

Fig. 26 Host-guest LEECs containing $\mathbf{5}$ or $\mathbf{6}$ as the blue/green host component and $\mathbf{3 5}$ as the red dopant. Device: ITO/PEDOT:PSS/5: [BMIM][PF $]$ ]: 35 (1: 0.35: 0.002 molar ratio)/Al, entry 2. Device: ITO/ PEDOT:PSS/6: [BMIM][PF6]: 35 (1: 1: 0.008 molar ratio)/Al, entry 3

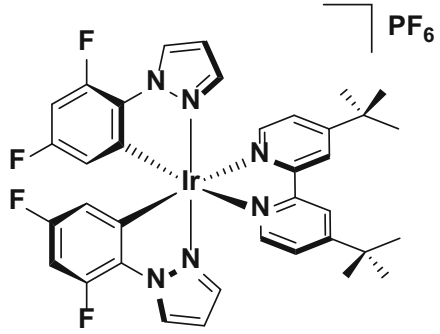

4<smiles>O=S(=O)(O)c1ccc(C2=c3cc4c5c(c3Oc3c2cc2c6c3CCCN6CCC2)CCC[N+]=5CCC4)c(S(=O)(=O)O)c1</smiles>

SR 101

Fig. 27 Host-guest LEEC containing $\mathbf{4}$ as the blue/green host component and SR $\mathbf{1 0 1}$ as the red dopant. Device: ITO/PEDOT:PSS/4 (79.5 wt \%), SR 101 (0.5 wt \%), [BMIM][PF $]$ (20 wt \%)/Ag, entry 4

is doped into the emissive layer along with 44. As mentioned, complex 22 is an effective electron transporting material, acting to improve carrier mobilities throughout the emissive layer and thus improve the efficiency. Indeed, the efficiency of the device (EQE $=6.3 \%$ ), entry 5, is almost double the efficiency of the control device utilizing only 4 and $\mathbf{4 4}$ in the emissive layer $(\mathrm{EQE}=3.2 \%)$.

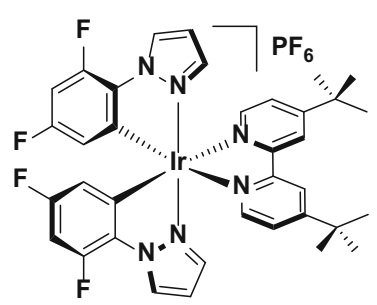

4

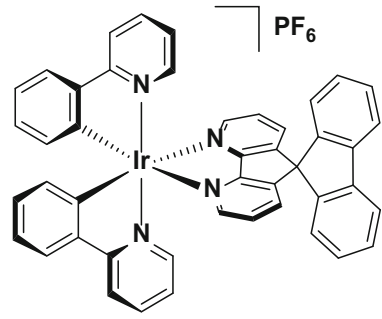

22

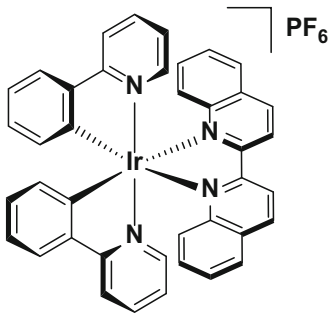

44

Fig. 28 Double-doped host-guest LEEC containing 4 as the blue/green host component, 22 as an orange-emitting electron transporting material and $\mathbf{4 4}$ as the red dopant. Device: ITO/PEDOT:PSS/4 (79.85 wt \%), 22 (0.05 wt \%), 44 (0.10 wt \%), [BMIM][PF $]$ (20.00 wt \%)/Al, entry 5 
Furthermore, since the orange emission of 22 in the solid state $\left(\lambda_{\mathrm{PL}}=593 \mathrm{~nm}\right)$ falls in between the emission of the host complex $4\left(\lambda_{\mathrm{PL}}=492 \mathrm{~nm}\right)$ and the red-emitting dopant $44\left(\lambda_{\mathrm{PL}}=672 \mathrm{~nm}\right)$, the overall color of the device is also not negatively impacted (CIE $0.32,0.43$ ) compared with the control device utilizing only 4 and 44 (CIE: 0.33, 0.42) [56] (Fig. 28).

\subsection{Multilayer LEECs}

Multilayer LEECs comprise much more varied device architectures than host-guest LEECs. For example, entry 6 is an example where a typical blue-green LEEC employing 4 as the emitter is capped on top of the ITO anode with a color conversion layer (CCL). This CCL is comprised of a transparent inert film doped with a small quantity red dye, such as DCJTB, and produces red light following photoexcitation by the blue-emitting component of the LEEC. Control of the doping concentration controls the relative contribution of blue and red light, and thus enables the generation of white light. Furthermore, this device achieves much higher efficiencies $(\mathrm{EQE}=12.5 \%)$ than the values reported for the host-guest LEECs in entries $1-5$.

However, an issue with this class of device is that since the chromophores generating white light are not excited simultaneously-as in the case of a typical host-guest device - the color of the device is strongly dependent on the amount of blue light output from the device. Since LEECs characteristically show variation in the luminance as a function of time, this ultimately leads to strong fluctuations in the CIE coordinates of the device with time. The degree of variability is dependent on the concentration of dye present in the CCL, with $0.3 \mathrm{wt} \%$ showing the least change in CIE coordinates, but nevertheless the coordinates are not consistent over a $0.5 \mathrm{~h}$ period [45, 54] (Fig. 29).

Since the performance of many white LEECs is ultimately governed by the performance of the blue-emitting iTMC, the device shown in entry 7 addresses this issue by doing away with a blue-emitting iTMC altogether, instead adopting a conjugated polyfluorene polymer CB02 (the full structure is not disclosed, appearing in the report exactly as shown in Fig. 30) as the blue-emitting

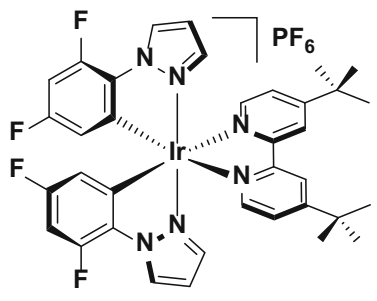

4

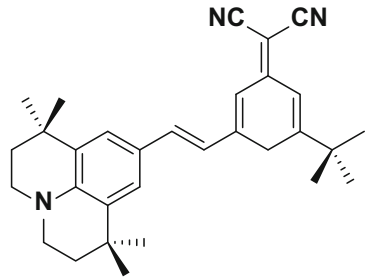

DCJTB

Fig. 29 Multilayer LEEC employing 4 as the blue/green component and DCJTB as the red-emitting dopant in the color conversion layer. Device: glass/photoresist film (99.7 wt \%), DCJTB (0.3 wt \%)/ITO/ PEDOT:PSS/4 (80.0 wt \%), [BMIM][PF $]$ (20.0 wt \%)/Ag, entry 6 
Fig. 30 Multilayer LEEC employing 25 as the orangeemitting layer and $\mathrm{CB} 02$ as the blue-emitting layer. Device: ITO/PEDOT:PSS/25, [BMIM] $\left[\mathrm{PF}_{6}\right] / \mathrm{CB} 02 / \mathrm{Ba} / \mathrm{Ag}$, entry 7

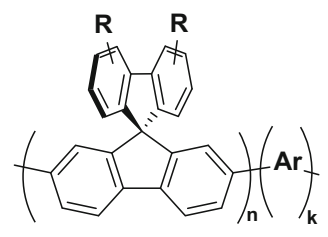

CBO2

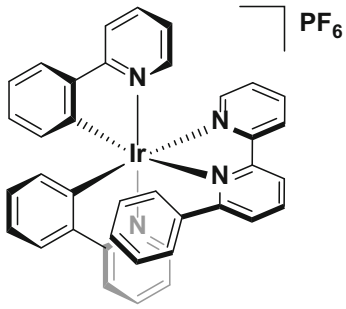

25

component. The device conveniently takes advantage of the 'orthogonal' solubility profiles of the iTMC 25 (spin-coated from MeCN) and CB02 (spin-coated from mesitylene), meaning that each layer can be sequentially deposited from solution without impacting the integrity of previously deposited layer, before encapsulation within the electrodes.

In contrast to the device in entry 6 , both emitters are excited electrically, with electrons injected into the CBO2 layer via the cathode and holes into the iTMC layer via the anode, recombining towards the interface of the two emissive layers. Since the CB02 layer is not charged, this device does not display typical 'LEEC behavior', showing no $J-V$ dependence as a function of time. This probably also accounts for the somewhat high driving voltages utilised for this device (7.0-10.0 V) compared with those discussed previously. Such high voltages also account for the much higher brightness for this device $\left(L_{\max }=\mathrm{ca} .400 \mathrm{~cd} \mathrm{~m}^{-2}\right.$ at $\left.7.0 \mathrm{~V}\right)$ compared with other white LEECs but this also appears to impact the efficiency, with only a relatively low current efficiency reported $\left(\mathrm{CE}=0.41 \mathrm{~cd} \mathrm{~A}^{-1}\right)$. Nevertheless, by controlling the relative thickness of the emissive layers (and thus the amount of light generated from each emitter), almost ideal white light can be achieved for this device (CIE 0.32, 0.34) [79].

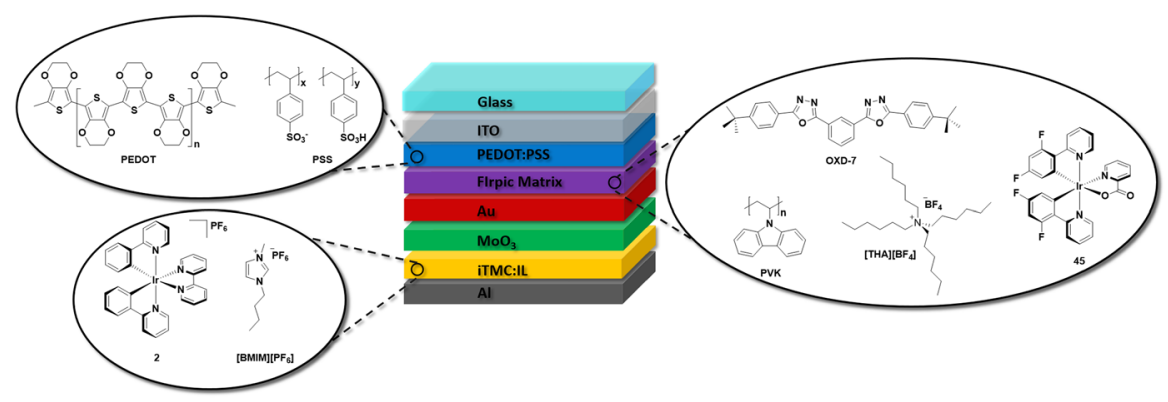

Fig. 31 Multilayer LEEC employing $\mathbf{2}$ as the yellow emitting layer and $\mathbf{4 5}$ as the blue-emitting layer. Device: ITO/PEDOT:PSS/PVK (43.5 wt \%), OXD-7 (43.5 wt \%), 45 (8.7 wt \%), [THA][BF 4 (4.3 wt $\%) / \mathrm{Au} / \mathrm{MoO}_{3} / 2(80.0 \mathrm{~mol} \%)$, [BMIM] $\left[\mathrm{PF}_{6}\right](20.0 \mathrm{~mol} \%) / \mathrm{Al}$, entry 8 , where PVK is poly(vinylcarbazole), OXD-7 is 1,3-bis(5-(4-(tert-butyl)phenyl)-1,3,4-oxadiazol-2-yl)benzene and [THA] $\left[\mathrm{BF}_{4}\right]$ is tetrahexylammonium tetrafluoroborate 
Arguably the most complex device is that of entry 8, which adopts a 'tandem LEEC' architecture to achieve white light. In this architecture, two sub-devices emitting yellow (2) and blue ('FIrpic', complex 45) light are stacked on top of each other, with an air stable middle electrode employed to separate the two devices. As with entry 7 , entry 8 borrows from well-established OLED literature to circumvent the issues with blue-emitting iTMCs, utilizing instead the well-known sky-blueemitting FIrpic complex. The blue LEEC adopts a typical OLED-type emissive layer, with the neutral complex $\mathbf{4 5}$ doped into a host of poly( $N$-vinylcarbazole) (PVK), which has hole transporting characteristics, and 2,2'-(1,3-phenylene)bis[5(4-tert-butylphenyl)-1,3,4-oxadiazole] (OXD-7, Fig. 31), which is an electron transporting material. An ionic liquid dopant (tetrahexylammonium tetrafluoroborate, $\left.[\mathrm{THA}]\left[\mathrm{BF}_{4}\right]\right)$ confers characteristic LEEC-type behavior, with the control device, ITO/PEDOT:PSS/PVK (43.5 wt \%), OXD-7 (43.5 wt \%), 45 (8.7 wt \%), $[\mathrm{THA}]\left[\mathrm{BF}_{4}\right](4.3 \mathrm{wt} \%) / \mathrm{Au}$, showing strong variations in luminance as a function of time. The use of a semi-transparent Au cathode allows for deposition of the second yellow-emitting component. In order to preserve the integrity of the Au surface, a thin $\mathrm{MoO}_{3}$ interlayer is also deposited. The second emissive layer of $\mathbf{2}$ is then added, followed by capping the device with an $\mathrm{Al}$ cathode.

Whereas entry 7 does not show normal LEEC behavior, the tandem LEEC, like the control based on $\mathbf{4 5}$, does show features typical of LEEC devices: upon applying a constant current, the driving voltage of the device drops rapidly, as ions in the emissive layers migrate to form the dynamically doped zones that facilitate the injection of electrons and holes. This phenomenon is common for conventional LEECs, but this is the only example of it being demonstrated in a double-stacked 'tandem LEEC' based on iridium. Overall, the performance of the device is very high: the luminance levels reported for this device $\left(L_{\max }=845 \mathrm{~cd} \mathrm{~m}^{-2}\right)$ are by far the highest reported for a white LEEC, while the efficiency $\left(\mathrm{CE}=8.5 \mathrm{~cd} \mathrm{~A}^{-1}\right)$ is comparable to some of the best host-guest LEECs described above. However, the CIE coordinates are somewhat shifted from the ideal white coordinate to "warm white' (CIE 0.38, 0.47).

\section{Conclusions and Outlook}

LEEC research is burgeoning owing to their attractively simple device architectures and facile processing from solution. These two features make these devices appealing for industrial applications, overcoming some of the fabrication drawbacks linked to OLEDs, which rely on costly multilayer device architectures that are typically fabricated by vacuum deposition methods.

In spite of the intrinsic simplicity of LEECs, recent developments in areas from the device architectures (host-guest systems, charge transport layers), to the synthesis of iTMCs (particularly silver-assisted methods) and methods of device operation (pulsed current LEECs) have culminated in reports demonstrating high device efficiencies (EQEs $>10 \%$ ) and stabilities ( $t_{1 / 2}$ of thousands of hours). However, even with these advances, the best performing LEECs fall well short of 
their OLED counterparts, with stabilities in LEECs in particular at least an order of magnitude lower.

Thus, the principal goal for researchers is still to address issues with respect to LEEC stability. In particular, LEECs still perform particularly poorly in the blue, deep-red, and white. There is therefore a dire need of further advances if these devices are to approach the performance metrics of leading OLEDs. In addition to more established strategies such as incorporating hydrophobic units within the ligand scaffold, several different approaches have begun to emerge that may tackle the difficulties present with devices of these colors. These include polymer-iTMC LEECs to the use of neutral blue emitters to overcome the lack of stable and efficient blue iTMCs. If the challenges relating to LEEC stability and the development of deep-blue devices can be overcome then the future of LEECs will be bright indeed.

Acknowledgments EZ-C acknowledges the University of St Andrews for financial support. We would like to thank the Engineering and Physical Sciences Research Council for financial support for Adam Henwood: EPSRC DTG Grants: EP/J500549/1; EP/K503162/1; EP/L505097/1.

Open Access This article is distributed under the terms of the Creative Commons Attribution 4.0 International License (http://creativecommons.org/licenses/by/4.0/), which permits unrestricted use, distribution, and reproduction in any medium, provided you give appropriate credit to the original author(s) and the source, provide a link to the Creative Commons license, and indicate if changes were made.

\section{References}

1. Baldo MA, O'Brien DF, You Y, Shoustikov A, Sibley S, Thompson ME, Forrest SR (1998) Nature 395:151. doi:10.1038/25954

2. Xu H, Chen R, Sun Q, Lai W, Su Q, Huang W, Liu X (2014) Chem Soc Rev 43:3259. doi:10.1039/ C3CS60449G

3. Yersin H, Rausch AF, Czerwieniec R, Hofbeck T, Fischer T (2011) Coord Chem Rev 255:2622. doi:10.1016/j.ccr.2011.01.042

4. Yang X, Xu X, Zhou G (2014) J Mater Chem C 3:913. doi:10.1039/c4tc02474e

5. Costa RD, Ortí E, Bolink HJ, Monti F, Accorsi G, Armaroli N (2012) Angew Chem Int Ed 51:8178. doi:10.1002/anie.201201471

6. Hu T, He L, Duan L, Qiu Y (2012) J Mater Chem 22:4206. doi:10.1039/C2JM16185K

7. Slinker JD, Rivnay J, Moskowitz JS, Parker JB, Bernhard S, Abruña HD, Malliaras GG (2007) J Mater Chem 17:2976. doi:10.1039/B704017B

8. Su H-C, Hsu J-H (2015) Dalton Trans 44:8330. doi:10.1039/C4DT01675K

9. Slinker JD, Gorodetsky AA, Lowry MS, Wang J, Parker ST, Rohl R, Bernhard S, Malliaras GG (2004) J Am Chem Soc 126:2763

10. Nonoyama M (1974) Bull Chem Soc Jpn 47:767. doi:10.1246/bcsj.47.767

11. Ladouceur S, Fortin D, Zysman-Colman E (2011) Inorg Chem 50:11514. doi:10.1021/ic2014013

12. Schneider GE, Bolink HJ, Constable EC, Ertl CD, Housecroft CE, Pertegas A, Zampese JA, Kanitz A, Kessler F, Meier SB (2014) Dalton Trans 43:1961. doi:10.1039/c3dt53229a

13. Zhao W, Liu C-Y, Wang Q, White JM, Bard AJ (2005) Chem Mater 17:6403. doi:10.1021/ $\mathrm{cm} 050375 \mathrm{p}$

14. Bünzli AM, Constable EC, Housecroft CE, Prescimone A, Zampese JA, Longo G, Gil-Escrig L, Pertegás A, Ortí E, Bolink HJ (2015) Chem Sci 6:2843. doi:10.1039/c4sc03942d

15. Baranoff E, Curchod BFE, Frey J, Scopelliti R, Kessler F, Tavernelli I, Rothlisberger U, Grätzel M, Nazeeruddin MK (2011) Inorg Chem 51:215. doi:10.1021/ic202162q 
16. Denisov SA, Cudré Y, Verwilst P, Jonusauskas G, Marín-Suárez M, Fernández-Sánchez JF, Baranoff E, McClenaghan ND (2014) Inorg Chem 53:2677. doi:10.1021/ic4030712

17. Tordera D, Delgado M, Ortí E, Bolink HJ, Frey J, Nazeeruddin MK, Baranoff E (2012) Chem Mater 24:1896. doi: $10.1021 / \mathrm{cm} 3011716$

18. Colombo MG, Güdel HU (1993) Inorg Chem 32:3081

19. Colombo MG, Hauser A, Güdel HU (1993) Inorg Chem 32:3088

20. Colombo MG, Hauser A, Güdel HU (1994) Top Curr Chem 171:143

21. Costa RD, Ortí E, Tordera D, Pertegás A, Bolink HJ, Graber S, Housecroft CE, Sachno L, Neuburger M, Constable EC (2011) Adv Energy Mater 1:282. doi:10.1002/aenm.201000069

22. Ladouceur S, Fortin D, Zysman-Colman E (2010) Inorg Chem 49:5625. doi:10.1021/ic100521t/

23. Costa RD, Ortì E, Bolink HJ, Graber S, Schaffner S, Neuburger M, Housecroft CE, Constable EC (2009) Adv Funct Mater 19:3456. doi:10.1002/adfm.200900911

24. Zhang J, Zhou L, Al-Attar HA, Shao K, Wang L, Zhu D, Su Z, Bryce MR, Monkman AP (2013) Adv Funct Mater 23:4667. doi:10.1002/adfm.201300344

25. Tordera D, Serrano-Pérez JJ, Pertegás A, Ortí E, Bolink HJ, Baranoff E, Nazeeruddin MK, Frey J (2013) Chem Mater 25:3391. doi:10.1021/cm402473j

26. Fernandez-Hernandez JM, Ladouceur S, Shen Y, Iordache A, Wang X, Donato L, Gallagher-Duval S, de Anda Villa M, Slinker JD, De Cola L, Zysman-Colman E (2013) J Mater Chem C. doi:10.1039/ C3TC31307G

27. Ladouceur S, Zysman-Colman E (2013) Eur J Inorg Chem 2013:2985. doi:10.1002/ejic.201300171

28. Cardona CM, Li W, Kaifer AE, Stockdale D, Bazan GC (2011) Adv Mater 23:2367. doi:10.1002/ adma.201004554

29. Bredas J-L (2014) Mater Horiz 1:17. doi:10.1039/c3mh00098b

30. Liao CT, Chen HF, Su HC, Wong KT (2012) Phys Chem Chem Phys 14:1262. doi:10.1039/ c1cp23336j

31. Pertegás A, Shavaleev NM, Tordera D, Ortí E, Nazeeruddin MK, Bolink HJ (2014) J Mater Chem C 2:1605. doi:10.1039/C3TC31983K

32. Ho C-C, Chen H-F, Ho Y-C, Liao C-T, Su H-C, Wong K-T (2011) Phys Chem Chem Phys 13:17729. doi:10.1039/C1CP21861A

33. Tamayo AB, Garon S, Sajoto T, Djurovich PI, Tsyba IM, Bau R, Thompson ME (2005) Inorg Chem 44:8723. doi:10.1021/ic050970t

34. Blasini DR, Rivnay J, Smilgies D-M, Slinker JD, Flores-Torres S, Abruna HD, Malliaras GG (2007) J Mater Chem 17:1458. doi:10.1039/B700505A

35. Liu C-Y, Bard AJ (2002) J Am Chem Soc 124:4190. doi:10.1021/ja0256156

36. Costa RD, Pertegás A, Ortí E, Bolink HJ (2010) Chem Mater 22:1288. doi:10.1021/cm903549u

37. Shen Y, Kuddes DD, Naquin CA, Hesterberg TW, Kusmierz C, Holliday BJ, Slinker JD (2013) Appl Phys Lett 102:203305. doi:10.1063/1.4807674

38. Lenes M, Garcia-Belmonte G, Tordera D, Pertegás A, Bisquert J, Bolink HJ (2011) Adv Funct Mater 21:1581. doi:10.1002/adfm.201002587

39. van Reenen S, Akatsuka T, Tordera D, Kemerink M, Bolink HJ (2012) J Am Chem Soc 135:886. doi:10.1021/ja3107803

40. Batagin-Neto A, Assis AP, Lima JF, Magon CJ, Yan L, Shao M, Hu B, Graeff CF (2014) J Phys Chem A. doi: $10.1021 / \mathrm{jp} 503831 \mathrm{p}$

41. Soltzberg LJ, Slinker JD, Flores-Torres S, Bernards DA, Malliaras GG, Abruña HD, Kim J-S, Friend RH, Kaplan MD, Goldberg V (2006) J Am Chem Soc 128:7761. doi:10.1021/ja055782g

42. Parker ST, Slinker JD, Lowry MS, Cox MP, Bernhard S, Malliaras GG (2005) Chem Mater 17:3187. doi:10.1021/cm050314r

43. Lee J, Chen H-F, Batagoda T, Coburn C, Djurovich PI, Thompson ME, Forrest SR (2016) Nat Mater 15:92. doi:10.1038/nmat4446. http://www.nature.com/nmat/journal/v15/n1/abs/nmat4446.html— supplementary-information

44. He L, Duan L, Qiao J, Wang R, Wei P, Wang L, Qiu Y (2008) Adv Funct Mater 18:2123. doi:10. 1002/adfm.200701505

45. Wu H-B, Chen H-F, Liao C-T, Su H-C, Wong K-T (2012) Org Electron 13:483. doi:10.1016/j.orgel. 2011.12.011

46. He L, Qiao J, Duan L, Dong G, Zhang D, Wang L, Qiu Y (2009) Adv Funct Mater 19:2950. doi:10. 1002/adfm.200900723

47. He L, Duan L, Qiao J, Dong G, Wang L, Qiu Y (2010) Chem Mater 22:3535. doi:10.1021/cm100993j 
48. Meier SB, Sarfert W, Junquera-Hernández JM, Delgado M, Tordera D, Ortí E, Bolink HJ, Kessler F, Scopelliti R, Grätzel M, Nazeeruddin MK, Baranoff E (2013) J Mater Chem C 1:58. doi:10.1039/ c2tc00251e

49. Zhang F, Duan L, Qiao J, Dong G, Wang L, Qiu Y (2012) Org Electron 13:1277. doi:10.1016/j.orgel. 2012.03.017

50. Zhang F, Duan L, Qiao J, Dong G, Wang L, Qiu Y (2012) Org Electron 13:2442. doi:10.1016/j.orgel. 2012.06.050

51. He L, Duan L, Qiao J, Zhang D, Wang L, Qiu Y (2011) Chem Commun 47:6467

52. Lowry MS, Goldsmith JI, Slinker JD, Rohl R, Pascal RA, Malliaras GG, Bernhard S (2005) Chem Mater 17:5712

53. Liao CT, Chen HF, Su HC, Wong KT (2012) Phys Chem Chem Phys 14:9774. doi:10.1039/ c2cp40739f

54. Lu J-S, Chen H-F, Kuo J-C, Sun R, Cheng C-Y, Yeh Y-S, Su H-C, Wong K-T (2015) J Mater Chem C 3:2802. doi:10.1039/c4tc02258k

55. Su H-C, Chen H-F, Chen P-H, Lin S-W, Liao C-T, Wong K-T (2012) J Mater Chem 22:22998

56. Su H-C, Chen H-F, Shen Y-C, Liao C-T, Wong K-T (2011) J Mater Chem 21:9653

57. Liao C-T, Chen H-F, Su H-C, Wong K-T (2011) J Mater Chem 21:17855. doi:10.1039/C1JM13245H

58. Darmawan N, Yang CH, Mauro M, Raynal M, Heun S, Pan J, Buchholz H, Braunstein P, De Cola L (2013) Inorg Chem 52:10756. doi:10.1021/ic302695q

59. Sivasubramaniam V, Brodkorb F, Hanning S, Loebl HP, van Elsbergen V, Boerner H, Scherf U, Kreyenschmidt M (2009) J Fluor Chem 130:640. doi:10.1016/j.jfluchem.2009.04.009

60. Zheng Y, Batsanov AS, Edkins RM, Beeby A, Bryce MR (2012) Inorg Chem 51:290. doi:10.1021/ ic $201655 n$

61. Bolink HJ, Coronado E, Costa RD, Ortì E, Sessolo M, Graber S, Doyle K, Neuburger M, Housecroft CE, Constable EC (2008) Adv Mater 20:3910

62. Costa RD, Ortí E, Bolink HJ, Graber S, Housecroft CE, Constable EC (2010) Adv Funct Mater 20:1511. doi:10.1002/adfm.201000043

63. Su HC, Fang FC, Hwu TY, Hsieh HH, Chen HF, Lee GH, Peng SM, Wong KT, Wu CC (2007) Adv Funct Mater 17:1019. doi:10.1002/adfm.200600372

64. Bolink HJ, Coronado E, Costa RnD, Lardiés N, Ortì E (2008) Inorg Chem. doi:10.1021/ic801587n

65. Tordera D, Frey J, Vonlanthen D, Constable E, Pertegás A, Ortí E, Bolink HJ, Baranoff E, Nazeeruddin MK (2013) Adv Energy Mater 3:1338. doi:10.1002/aenm.201300284

66. Evariste S, Sandroni M, Rees TW, Roldan-Carmona C, Gil-Escrig L, Bolink HJ, Baranoff E, Zysman-Colman E (2014) J Mater Chem C 2:5793. doi:10.1039/C4TC00542B

67. Su H-C, Chen H-F, Wu C-C, Wong K-T (2008) Chem-Asian J. doi:10.1002/asia.200800020

68. Costa RD, Ortí E, Bolink HJ, Graber S, Housecroft CE, Neuburger M, Schaffner S, Constable EC (2009) Chem Commun (Camb). doi:10.1039/b821602a

69. Costa RD, Ortí E, Bolink HJ, Graber S, Housecroft CE, Constable EC (2010) J Am Chem Soc. doi: $10.1021 /$ ja1010674

70. Sun L, Galan A, Ladouceur S, Slinker JD, Zysman-Colman E (2011) J Mater Chem 21:18083

71. Tordera D, Meier S, Lenes M, Costa RD, Ortí E, Sarfert W, Bolink HJ (2012) Adv Mater 24:897. doi:10.1002/adma.201104047

72. Tordera D, Pertegás A, Shavaleev NM, Scopelliti R, Ortí E, Bolink HJ, Baranoff E, Grätzel M, Nazeeruddin MK (2012) J Mater Chem 22:19264. doi:10.1039/c2jm33969b

73. Zysman-Colman E, Slinker JD, Parker JB, Malliaras GG, Bernhard S (2008) Chem Mater 20:388

74. Costa RD, Cespedes-Guirao FJ, Orti E, Bolink HJ, Gierschner J, Fernandez-Lazaro F, Sastre-Santos A (2009) Chem Commun (Camb). doi:10.1039/b905367k

75. Hasan K, Donato L, Shen Y, Slinker JD, Zysman-Colman E (2014) Dalton Trans. doi:10.1039/ C4DT02100B

76. Graber S, Doyle K, Neuburger M, Housecroft CE, Constable EC, Costa RD, Orti E, Repetto D, Bolink HJ (2008) J Am Chem Soc 130:14944. doi:10.1021/ja805900e

77. Rodriguez-Redondo JL, Costa RD, Orti E, Sastre-Santos A, Bolink HJ, Fernandez-Lazaro F (2009) Dalton Trans:9787

78. Su H-C, Chen H-F, Fang F-C, Liu C-C, Wu C-C, Wong K-T, Liu Y-H, Peng S-M (2008) J Am Chem Soc 130:3413. doi:10.1021/ja076051e

79. Sessolo M, Tordera D, Bolink HJ (2013) ACS Appl Mater Interfaces 5:630. doi:10.1021/am302033k

80. Akatsuka T, Roldan-Carmona C, Orti E, Bolink HJ (2014) Adv Mater 26:770. doi:10.1002/adma. 201303552 